\title{
Airbnb: ¿economía colaborativa o nuevo modelo de negocio? Evidencia empírica reciente desde una ciudad de tamaño medio como Bilbao
}

\author{
Airbnb: sharing economy or a new business model? \\ Recent empirical evidence from a medium-sized city like Bilbao
}

\author{
Itziar Aguado-Moralejo ${ }^{1^{*}}$ \\ Carmen Echebarria ${ }^{2}$ (iD) \\ José M. Barrutia ${ }^{3}$
}

\section{Resumen}

La economía colaborativa, es un concepto controvertido y polémico construido en torno al avance de las tecnologías de la información y comunicación, las plataformas digitales y el intercambio (generalmente, ocasional y por tiempo limitado) de activos infrautilizados entre proveedores y consumidores. Airbnb, la plataforma digital líder en alquiler turístico, defiende que sus actividades responden a este nuevo modelo económico, especialmente debido al servicio de alquiler de viviendas compartidas. Este artículo, a partir del tratamiento y depuración de diferentes fuentes estadísticas y cartográficas, (1) amplia la evidencia empírica sobre las actividades de Airbnb en una ciudad de tamaño medio como Bilbao, y (2) analiza la caracterización de la oferta de Airbnb en Bilbao y su grado de contribución a la economía colaborativa. El análisis muestra claramente que "compartir el hogar" es relevante, pero la oferta comercial es también muy significativa, aunque geográficamente desigual, en la forma en que la plataforma opera en la ciudad. En cualquier caso, las plataformas digitales constituyen una parte cada vez más relevante de las actividades de alojamiento turístico a nivel mundial, por lo que es necesario profundizar más en el debate sobre la relación entre las plataformas y la economía colaborativa.

Palabras clave: Airbnb; plataformas digitales; alquiler turístico; economía colaborativa; Bilbao.

\begin{abstract}
The sharing economy is a controversial concept built around the advancement of information and communication technologies, digital platforms, and the exchange (usually occasional and for a limited time) of underused assets between suppliers and consumers. Airbnb, the leading digital platform connecting hosts with guests, argues that its activities respond to this new economic model, especially the service of shared rental housing. This article, based on the treatment and refinement of different statistical and cartographic sources: (1) broadens the base of empirical evidence on Airbnb's activities in a medium-sized European city like Bilbao; and (2) analyses what Airbnb's offer in Bilbao tells us about

\footnotetext{
1 Departamento de Geografía, Prehistoria y Arqueología. Universidad del País Vasco (UPV/EHU), España. itziar.aguado@ehu.eus. *Autora para correspondencia

2 Departamento de Economía Aplicada I. Universidad del País Vasco (UPV/EHU), España. carmen.etxebarria@ehu.eus

3 Departamento de Economía Financiera II. Universidad del País Vasco (UPV/EHU), España. josemaria.barrutia@ehu.eus
} 
the degree to which Airbnb contributes to the sharing economy. The analysis clearly shows that 'homesharing' is relevant, but the commercial offer is also highly significant, although geographically uneven, in the way that the platform operates in the city. Digital platforms are an increasingly relevant part of tourist accommodation activities worldwide, and it is, therefore, necessary to go deeper into the debate on the relationship between platforms and the sharing economy.

Keywords: Airbnb; digital platforms; tourist rental; sharing economy; Bilbao.

\section{Introducción}

En los últimos años, el importante desarrollo de las tecnologías de la información y comunicación (TIC), ha posibilitado el encuentro entre consumidores y proveedores (Schor, 2016), ha permitido la reducción de los costes de las transacciones y ha facilitado el cambio en el comportamiento de los usuarios (Jarne Muñoz, 2016), impulsando, de este modo, un nuevo modelo económico que lleva a que la conocida como economía colaborativa se esté introduciendo paulatinamente en nuestro día a día (Zervas, Proserpio \& Byers, 2017). La economía colaborativa se refiere a un nuevo sistema de producción y consumo que hace uso de las TIC para intercambiar y compartir bienes y/o servicios a través de plataformas digitales (Acquier, Carbone \& Massé, 2019). En función de si la plataforma actúa como prestador o como intermediario, se podrán establecer diferentes modelos de negocio pudiéndose hablar de conceptos tales como el "cooperativismo de plataforma" o el "capitalismo de plataforma", cuya diferencia principal reside en la titularidad de la empresa y en el papel que ejerce la plataforma como intermediario o como prestador del servicio y/o bien (Alfonso Sánchez, 2016; Alfonso Sánchez \& Burillo, 2016). También conviene identificar la existencia o no de un propósito de lucro en los agentes que participan, con objeto de crear políticas públicas diferenciadas (Cañigueral, 2016). Incluye, en este sentido, tanto el consumo colaborativo como los mercados de redistribución (Bruno \& Faggini, 2017). De hecho, se trata de un modelo económico complejo que puede afectar a cuatro esferas diferentes: consumo colaborativo, producción contributiva, finanzas peer-to-peer y conocimiento abierto (Enciso, Mugarra, Muñecas \& Ruiz, 2019).

En este contexto, diferentes sectores (turismo, transporte, comercio, cultura, etc.), no han sido ajenos a esta evolución de las tecnologías de la información y comunicación y la economía colaborativa ha irrumpido con fuerza, emergiendo nuevos modelos de negocio basados en plataformas digitales que están transformando el modo de alojarse (como Airbnb, Windu o Homeway), de desplazarse (como Uber, BlaBlaCar o Cabify), realizar actividades comerciales (Shopify, PrestaShop o WooCommerce) o disfrutar de actividades culturales (Hipermedula, SoundCloud o Saatchi Art). Estos modelos de negocio vinculan la oferta con la demanda de servicios o bienes a través de un modelo peer-to-peer que aporta la posibilidad de contratación en tiempo real, pudiendo poner en valor recursos ociosos y reduciendo los costes de transacción (Sastre-Centeno \& Inglada-Galiana, 2018). También ponen en valor activos infrautilizados y los hacen accesibles para una comunidad, lo que conlleva una menor necesidad de propiedad de dichos activos.

Centrándonos en el sector turístico y, más en concreto, en la oferta de alquileres de viviendas por parte de la plataforma Airbnb, este artículo pretende explorar las relaciones entre la irrupción del alquiler de viviendas por parte de Airbnb y la economía colaborativa. Airbnb, fundada en 2007 en San Francisco, en Estados Unidos, es la empresa líder indiscutible en su rama de actividad, gestiona actualmente 5,6 millones de propiedades en todo el mundo y tiene presencia en más de 220 países (Airbnb, Inc., 2021) El espectacular crecimiento a nivel mundial que ha tenido Airbnb en poco más de una década de existencia, tanto en número de usuarios como en beneficios, ha generado un debate creciente en la literatura sobre sus impactos económicos, sociales y espaciales.

En numerosas ciudades como San Francisco, Nueva York, Barcelona, Berlín, París, Bruselas o Ámsterdam, la oferta de Airbnb supera ya a la oferta hotelera convencional (Oskam \& Boswijk, 2016; Adamiak, 2018; 2019; Heo, Blal, \& Choi, 2019), por lo que los gobiernos han empezado a regular estas actividades con objeto de establecer más claramente las reglas del juego (Gurran \& Phibbs, 2017; Adamiak, 2018; Nieuwland \& Van Melik, 2020). Así numerosos gobiernos municipales están aplicando viejas regulaciones a estos nuevos negocios, sin reflexionar en profundidad sobre si dichas normas son aplicables a estas empresas de ámbito internacional y sin alcanzar a comprender completamente los beneficios e inconvenientes que pueden generar (Quattrone et al., 2016).

Airbnb señala que sus actividades entran dentro de la economía colaborativa ya que son los propios particulares quienes ofertan, a través de la plataforma, sus viviendas para alojamiento turístico en una 
relación peer-to-peer con los consumidores. De esta forma, se genera una fuente de ingresos adicional para los propietarios que ofertan sus viviendas (Botsman \& Rogers, 2010), realizando una oferta diversa de alojamientos a precios más reducidos que los que realiza la oferta hotelera tradicional en aquellas áreas de la ciudad donde no existen plazas hoteleras o un suficiente número de estas, contribuyendo así a distribuir la afluencia turística a otros barrios periféricos de la ciudad y a promover experiencias de turismo alternativas a las tradicionales (Paulauskaite, Powell, Coca-Stefaniak \& Morrison et al., 2017; Wang \& Nicolau, 2017). Por el contrario, quienes critican estas prácticas argumentan que no son los particulares y las familias con ingresos reducidos quienes componen la oferta de alojamientos de alquiler dentro de la plataforma Airbnb, sino que esta es controlada, fundamentalmente, por los grandes propietarios, por lo que dichas actividades no se ajustan al esquema de la economía colaborativa (Arias Sans \& Quaglieri-Domínguez, 2016; Cocola-Gant \& Gago, 2019; Yrigoy, 2019; Gil \& Sequera, 2020; Dogru, Mody, Suess, Line \& Bonn et al, 2020).

Por todo ello, se ha empezado ya a estudiar el fenómeno de Airbnb y su relación con la economía colaborativa en ciudades especialmente turísticas a nivel mundial como San Francisco (Brousseau, 2015), Nueva York (Sheppard \& Udell, 2016), Berlín (Schäfer \& Braun, 2016; Duso, Michelsen, Schäfer \& Tran et al., 2020), Milán (Amore, Bernardi \& Arvanitis, 2020), París (Freytag \& Bauder, 2018), Lisboa (Cocola-Gant \& Gago, 2019; Sequera \& Nofre, 2020); Barcelona (Arias Sans \& Quaglieri-Domínguez, 2016) o Madrid (Gil \& Sequera, 2020). Sin embargo, se ha prestado mucha menor atención por parte de los investigadores a la presencia y efectos de este fenómeno en ciudades de menor tamaño y con menor número de turistas (Adamiak, 2019).

Con el fin de contribuir empírica y metodológicamente a la base de evidencia, este análisis se centrará en Bilbao, una ciudad española de tamaño medio que lleva experimentando un proceso continuo de revitalización y transformación desde hace más de veinticinco años, lo que le ha aportado un importante atractivo turístico (Plaza \& Haarich, 2015) y ha generado la oferta de alojamientos turísticos a través de plataformas digitales y, en particular, a través de Airbnb.

Hasta ahora, los estudios empíricos sobre ciudades europeas se han centrado en los principales destinos turísticos con mayor número de turistas (París, Londres, Berlín, Barcelona, Madrid, Lisboa, Palma de Mallorca). No obstante, si bien centrarse en las ciudades con mayor número de turistas proporciona información relevante sobre la implantación y desarrollo de este nuevo modelo de negocio, el análisis de estas deja sin responder cómo les está yendo a las ciudades con menor número de turistas, en términos de la oferta de Airbnb. Dado que los pocos análisis disponibles encuentran diferencias considerables en la estructura de la oferta de Airbnb según el tamaño de la ciudad y el contexto local (Adamiak, 2018), parece necesario ampliar el enfoque de los estudios e incluir en ellos el análisis de un abanico más amplio de ciudades.

Para el estudio del caso de la ciudad de Bilbao, se plantean las siguientes preguntas clave: ¿Dónde se localizan los alojamientos turísticos ofertados por Airbnb en Bilbao? ¿Se puede ubicar la oferta de Airbnb en Bilbao dentro de la economía colaborativa o se trata de una oferta profesionalizada? ¿Se encuentra homogéneamente distribuida la oferta de alojamientos de Airbnb en la ciudad? ¿En caso negativo, dónde se localiza la mayor concentración de la oferta? ¿Se trata de una oferta alternativa a la oferta hotelera tradicional o supone una competencia para la misma? ¿Influyen las características del tejido residencial existente en los barrios en la oferta de alojamientos de Airbnb? ¿Qué datos arroja el análisis de las actividades de Airbnb en Bilbao sobre el grado en que Airbnb contribuye a la economía colaborativa?

En consecuencia, a partir del tratamiento y depuración de diferentes fuentes estadísticas y cartográficas, este artículo pretende alcanzar los siguientes objetivos: (1) proporcionar un análisis de la espacialidad de la oferta de alquileres de la plataforma digital Airbnb en Bilbao y de las características específicas de dicha oferta, y (2) estudiar el grado en que Airbnb contribuye a la economía colaborativa en la ciudad de Bilbao.

Por último, el artículo se estructura de la siguiente manera: tras esta breve referencia introductoria, la siguiente sección se centra en la metodología que, por un lado, presenta el área de estudio y, por otro lado, describe las fuentes de datos y el método de investigación. La tercera sección ofrece los resultados del análisis, mientras que la cuarta sección presenta la discusión. Por último, la sección final presenta las principales conclusiones del trabajo y las vías de investigación futuras. 


\section{Metodología}

\subsection{Presentación del área de estudio}

Bilbao es la ciudad más grande del País Vasco (Figura 1), con una población de 343.430 habitantes (Instituto Vasco de Estadística [Eustat], 2019c), siendo la cabecera de la Comarca del Gran Bilbao (comprende el municipio de Bilbao y veinticinco municipios más), cuya población asciende a 858.236 (Eustat, 2019c), y representa el 40 por ciento de la población total del País Vasco. Económicamente, Bilbao ha sido desde el siglo XIX un polo industrial de gran importancia, lo que le supuso un aumento continuo de su población hasta la década de los años ochenta del pasado siglo. En esos años, la crisis industrial le azotó con fuerza, obligándole a afrontar un traumático proceso de reconversión industrial y a apostar por una importante política de revitalización económica y rehabilitación urbana (Aguado-Moralejo, Echebarria \& Barrutia, 2019; Franklin, 2016). Este esfuerzo ha supuesto el reconocimiento a nivel nacional e internacional de su proceso de transformación urbana, pasando en unas pocas décadas de ser una ciudad industrial a convertirse en una ciudad de servicios con un elevado y creciente atractivo turístico (González, 2011; Plaza \& Haarich, 2015). Esta transformación, originariamente asentada en políticas de regeneración física y urbanística con actuaciones como la recuperación fluvial de la ría, la mejora de las infraestructuras de transporte, la generación de espacios residenciales de calidad o el desmantelamiento de distintas zonas industriales y la construcción sobre ellas de infraestructuras culturales como el icónico Museo Guggenheim Bilbao y el Palacio Euskalduna, se basa, actualmente, en actuaciones mucho más fragmentadas y fuertemente condicionadas por las fuerzas del mercado, junto con un gran proyecto de remodelación del área de Zorrotzaurre con base en el Master Plan de Zaha Hadid (Gainza, 2017).

Figura 1. El municipio de Bilbao y sus barrios
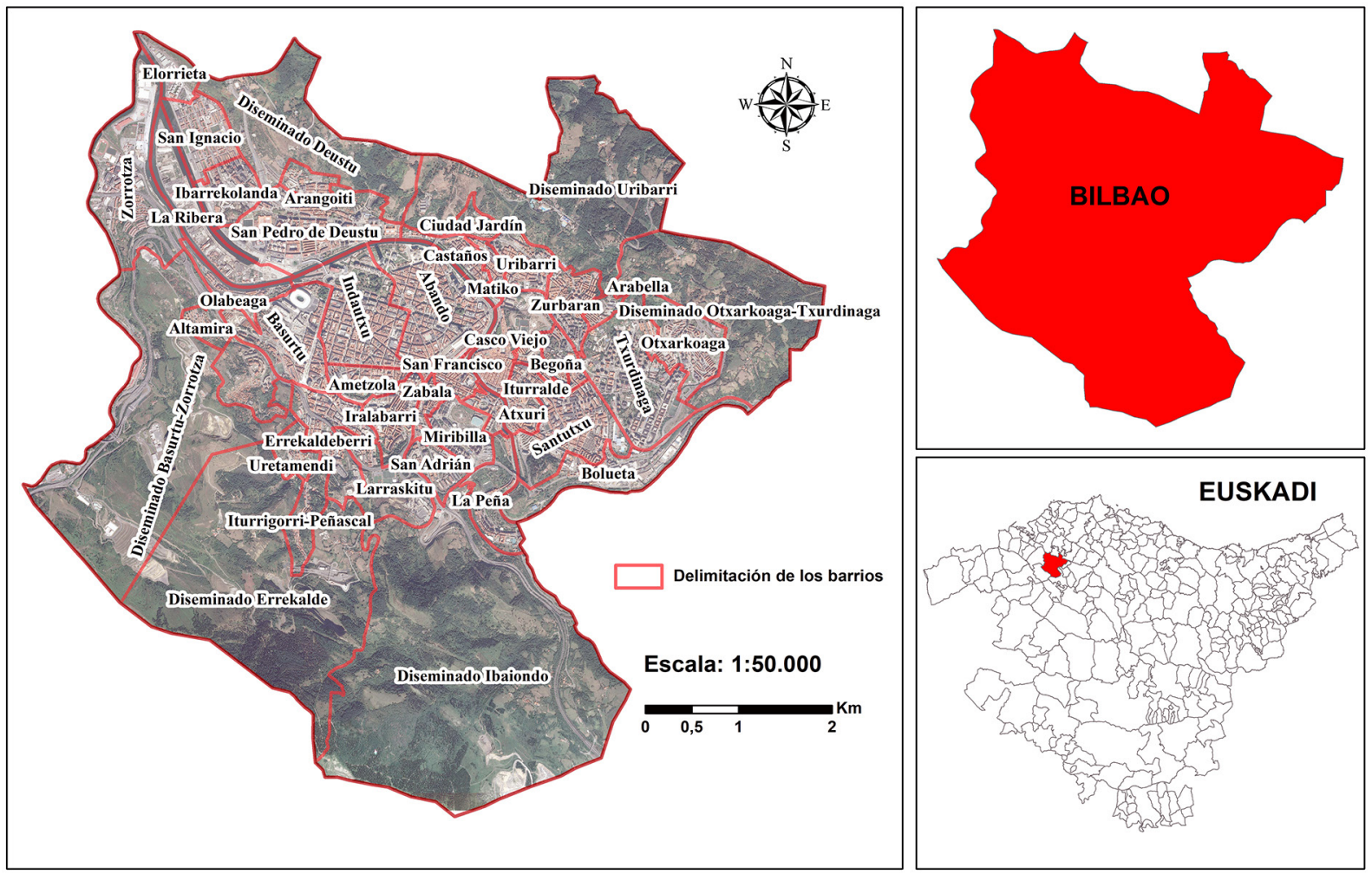

Fuente: Geoeuskadi. Elaboración propia

En este marco, la creciente llegada de visitantes a Bilbao ha propiciado la ampliación y diversificación del modelo turístico, inicialmente centrado en el turismo de negocios, hacia otro tipo de servicios turísticos, empezándose a ofertar en la ciudad alojamientos turísticos a través de plataformas digitales. La plataforma Airbnb, aunque de reciente implantación, pero en crecimiento, ya recoge el mayor número de alquileres turísticos, superando a otras plataformas como Wimdu y Niumba (Fierro \& Salmón, 2018; Palos-Sánchez \& Correia, 2018; Adamiak, Szyda, Dubownik \& García-Álvarez, 2019). 
Esta proliferación de alojamientos turísticos, dio lugar a que en 2017 se modificase el Plan General de Ordenación Urbana de Bilbao con el fin de poder regular esta oferta y garantizar una mejor praxis turística. Más en concreto, por un lado, se categorizaron cuatro modalidades de alojamiento: (1) hoteles, hostales y pensiones (referido a la oferta tradicional, cuya regulación ya estaba establecida), (2) apartamentos turísticos y apartahoteles (aquellos que cuentan, además de la zona de dormitorio, con un aseo y una cocina), (3) vivienda turística (dedicadas exclusivamente para uso turístico y que solamente pueden estar ubicadas en la primera planta de los edificios de uso residencial), y (4) habitaciones turísticas (el propietario de la vivienda que se oferta debe estar empadronado en la vivienda ofertante); estableciéndose una regulación diferenciada en función de dichas modalidades. Y, por otro lado, se adoptaron mayores restricciones en los barrios más sometidos a presión turística, como el Casco Viejo y Bilbao la Vieja, permitiendo sólo una actividad turística por edificio (Ayuntamiento de Bilbao, 2017).

Aunque es difícil obtener cifras comparables, estadísticas recientes del Bilbao Turismo \& Convention Bureau señalan que, en 2019, la ciudad tuvo casi dos millones de pernoctaciones (Bilbao Turismo \& Convention Bureau, 2020). El número de turistas (nacionales e internacionales) ha aumentado rápidamente y se ha incrementado en más del $20 \%$ por ciento en los últimos cinco años (Bilbao Turismo \& Convention Bureau, 2020). Sin embargo, Bilbao se encuentra claramente por detrás de las principales ciudades turísticas españolas y europeas. Si se toma el número de llegadas internacionales como indicador, Barcelona superó los 7 millones y Madrid estuvo cerca de los 5 millones y medio en 2019 (INE, 2020), mientras que Bilbao no llegó a las 500.000 llegadas internacionales. También en términos del total de pernoctaciones, Bilbao no aparece entre los principales destinos, ya que Barcelona, Madrid y Palma de Mallorca tuvieron, respectivamente, 21,4 millones, 20,85 millones y 8,9 millones de pernoctaciones, lo que convierte a Bilbao en un destino en crecimiento, aunque no principal, en comparación con los destinos anteriores (INE, 2020).

No obstante, aunque el turismo nacional e internacional se ha convertido en una de las principales fuerzas impulsoras de la reciente remodelación de Bilbao, geográficamente, las actividades turísticas y los alojamientos se distribuyen de manera desigual en la ciudad, con concentraciones diversas en los diferentes barrios.

Hasta fechas muy recientes, Bilbao tenía una oferta de alojamientos turísticos en crecimiento en cuanto a hoteles y pensiones, con un papel más limitado para los apartamentos vacacionales. A finales de 2019, solo 782 proveedores de apartamentos estaban registrados en la ciudad, quienes, en conjunto, proporcionaron 1.168 alojamientos. En comparación, los hoteles y pensiones ofrecieron unas 7.500 camas (Gobierno Vasco, 2020). Sin embargo, en este marco, Airbnb ha crecido rápidamente. Mientras que a finales de 2017 había unos 966 apartamentos disponibles, en el cuarto trimestre de 2019, se registraron 1.198 alquileres activos (Inside Airbnb, 2019), lo que representa un aumento del 25\% en sólo dos años. Aunque Airbnb argumenta habitualmente que su servicio opera fuera de los barrios turísticos tradicionales, en Bilbao la oferta de Airbnb se agrupa en los barrios del centro de la ciudad (Figura 2), lo que refleja, en un grado considerable, la geografía de los alojamientos turísticos en general. Los patrones espaciales de Airbnb difieren según el tipo de alojamiento, con predominio de viviendas o apartamentos enteros ubicados en el centro de la ciudad y habitaciones compartidas en la periferia.

\subsection{Fuentes de datos}

Para realizar el análisis, se han utilizado las siguientes fuentes de datos. En primer lugar, los datos sobre los indicadores dependientes de los listados de alquileres de alojamientos de Airbnb, se obtuvieron a partir de la página web http://insideairbnb.com, una plataforma independiente y no comercial que ofrece información recopilada del sitio web oficial de Airbnb. Dicha plataforma, creada por Murray Cox (que se autodefine como activista comunitario y tecnólogo), ofrece un listado completo de los alojamientos de Airbnb en distintas ciudades. Para cada alojamiento registra sus coordenadas geográficas, la tipología de alquiler, el nombre de su propietario, la descripción sintética, el precio, el número mínimo de noches, la disponibilidad anual, las críticas recibidas y el número de alojamientos ofertados por dicho usuario. Para este trabajo, se recopilaron los anuncios de alquileres turísticos relativos a Euskadi-País Vasco disponibles a fecha 31 de diciembre de 2019. Después de eliminar los alojamientos ofertados por Airbnb no correspondientes al municipio de Bilbao, se georreferenciaron mediante ArcGis y se ubicaron en sus respectivos barrios. En total, se identificaron 1.156 alojamientos tras haber descartado los que no disponían de información completa o no se correspondían con las siguientes modalidades de alojamiento analizadas: alquiler íntegro, habitación privada y habitación compartida. De hecho, se identificaron también ofertas que 
se correspondían con establecimientos hoteleros tradicionales que también se publicitaban a través de la plataforma. En segundo lugar, los mapas necesarios para realizar la cartografía se descargaron del servicio GeoEuskadi (https://www.geo.euskadi.eus), utilizándose los barrios administrativos de Bilbao como unidades de análisis, aunque no se consideraron las entidades diseminadas ni el barrio de Elorrieta, por ser un barrio en proceso de construcción del que no se dispone aún de datos estadísticos. La información relativa a los establecimientos hoteleros o turísticos se descargó de la plataforma de datos abiertos Opendata Euskadi (https://opendata.euskadi.eus) donde se recoge el listado recopilado por el Gobierno Vasco (2020). En tercer y último lugar, para contextualizar los resultados y entender las características particulares de cada barrio, se acudió a distintas fuentes de datos que ofrecen información sociodemográfica a esta escala territorial, tales como la Estadística Municipal de Habitantes (Eustat, 2019c), la Estadística Municipal de Educación (Eustat, 2019b), la Estadística Municipal de Actividad (Eustat, 2019a), la Estadística de Renta Personal y Familiar (Eustat, 2018), Estadística Municipal de Viviendas (Eustat, 2019d), la Estadística del Mercado de Alquiler (Departamento de Planificación Territorial, Vivienda y Transportes, 2019) y Promociones de Vivienda Protegida (Observatorio Vasco de la Vivienda, 2020).

\subsection{Método de investigación}

El método de investigación utilizado consistió en la elaboración de datos cuantitativos mediante la aplicación de diferentes técnicas estadísticas y cartográficas. Por ello, en primer lugar, para caracterizar la oferta de alojamientos de Airbnb en Bilbao, se realizó un análisis estadístico descriptivo y una serie de análisis estadísticos bivariados con el fin de identificar las correlaciones existentes entre las distintas variables consideradas. En segundo lugar, como soporte visual, se cartografió la información a escala barrial mediante la utilización del programa ArcGIS, con el propósito de analizar de forma pormenorizada la distribución de los alojamientos en la ciudad.

Para completar el análisis, se utilizaron las herramientas de análisis espacial de ArcGIS, en concreto, el estadístico I de Moran, uno de los índices más extendidos para identificar la existencia de autocorrelación espacial (Gutiérrez et al., 2017; Adamiak et al., 2019; Kadi, Plank \& Seidl, 2019). Este estadístico, sostiene como hipótesis nula que la distribución de las variables es aleatoria (Moran, 1948) y sirve para analizar si existen efectos espaciales en las variables estudiadas derivadas de la contigüidad física, criterio al que se conoce como vecindad. En particular, la estadística de autocorrelación espacial I de Moran muestra la relevancia del sesgo espacial de los fenómenos espaciales. La estadística fue introducida por primera vez por Moran (1948) y posteriormente fue desarrollada por Cliff y Ord (1970) basándose en la conocida como Ley de Tobler que señala que todo está relacionado con todo, pero las cosas más cercanas están más relacionadas que las más alejadas (Tobler, 1970). De esta forma, se pudo medir el grado de asociación de la cantidad de alojamientos que Airbnb presenta a nivel barrial en Bilbao y determinar sus patrones espaciales (Anselin, 1995; Eugenio-Martin, Cazorla-Artiles \& González-Martel, 2019). También permitió analizar el grado de afectación de otras unidades territoriales vecinas —en este caso, barrios-, en orden a detectar si existe interrelación entre la oferta en los barrios colindantes. Finalmente, se compararon los datos anteriores con una serie de variables estadísticas relativas a la población y a la vivienda.

\section{Resultados del análisis}

\section{1. ¿Dónde se localizan los alojamientos ofertados por Airbnb en Bilbao?}

Una visualización cartográfica del cómputo total de alojamientos ofertados por Airbnb por barrios (Figura 2) refleja que dichos alojamientos se concentran en los barrios centrales de Bilbao, fundamentalmente en los barrios de Abando y Casco Viejo, mientras que apenas se encuentra presencia de este tipo de alojamientos en los barrios más periféricos.

Sin embargo, si se analizan los alojamientos ofertados por Airbnb con relación al número de viviendas de cada barrio en términos porcentuales, la imagen que muestra el mapa de Bilbao es distinta (Figura 3), ya que, en este caso, existen barrios periféricos, especialmente Ciudad Jardín, pero también La Ribera y Olabeaga, donde se dan porcentajes relativamente altos de alojamientos de alquiler turístico. Este resultado puede deberse a que en estos barrios el parque residencial es reducido y no cuentan con un volumen amplio de viviendas. Además, en este mapa se evidencia que, en términos relativos, Abando pierde posiciones y que junto con el Casco Viejo y Ciudad Jardín aparecen otros barrios, como Bilbao La Vieja y San Francisco, donde se produce también una elevada concentración de alojamientos Airbnb. 
Figura 2. Cómputo total de los alojamientos ofertados por Airbnb en Bilbao por barrios. 2019

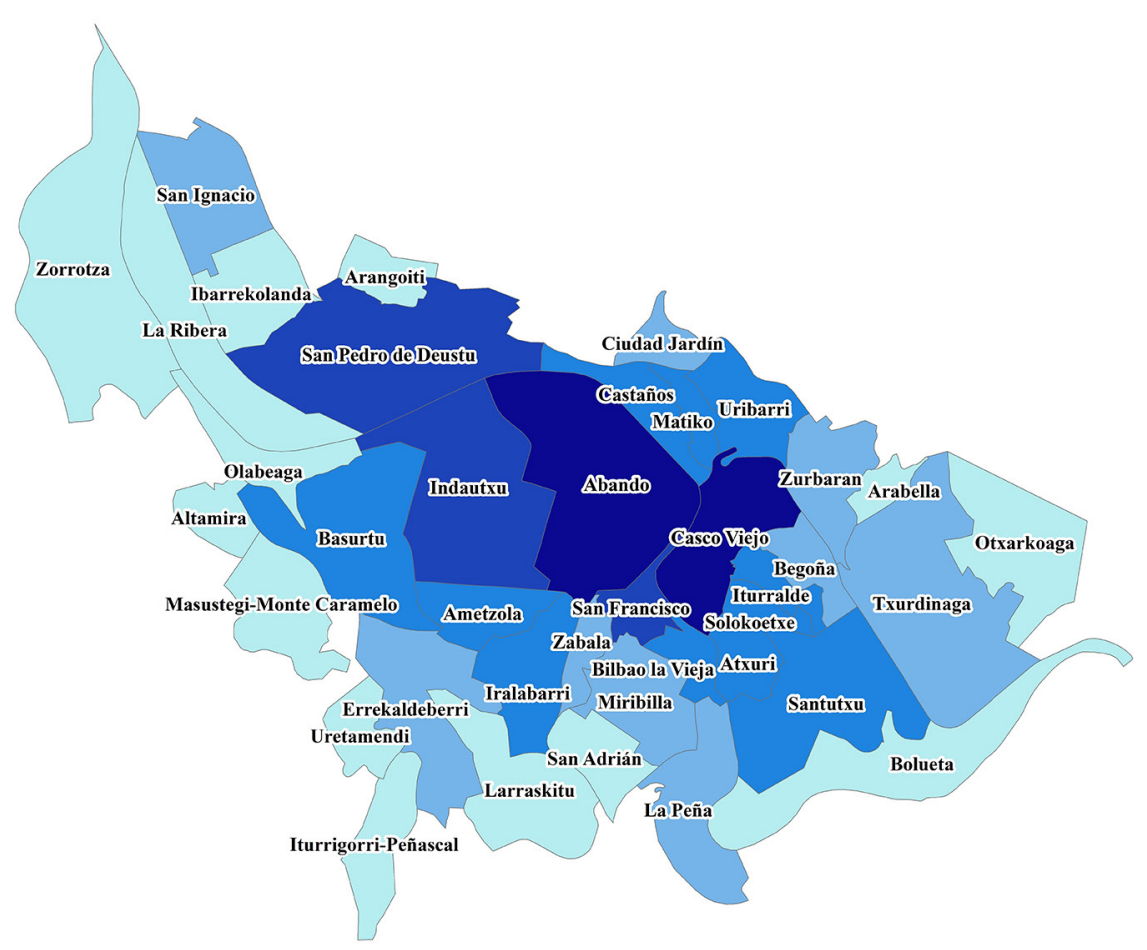

\begin{abstract}
Alojamientos Airbnb por barrios (en cifras absolutas)
\end{abstract}

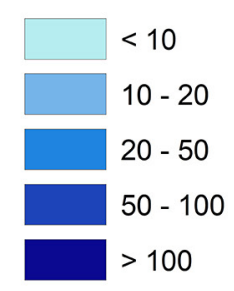

Escala: 1:25.000

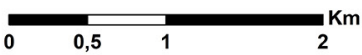

Fuente: datos de Inside Airbnb (2019). Elaboración propia

Figura 3. Alojamientos ofertados por Airbnb en Bilbao en relación al número de viviendas por barrios. 2019
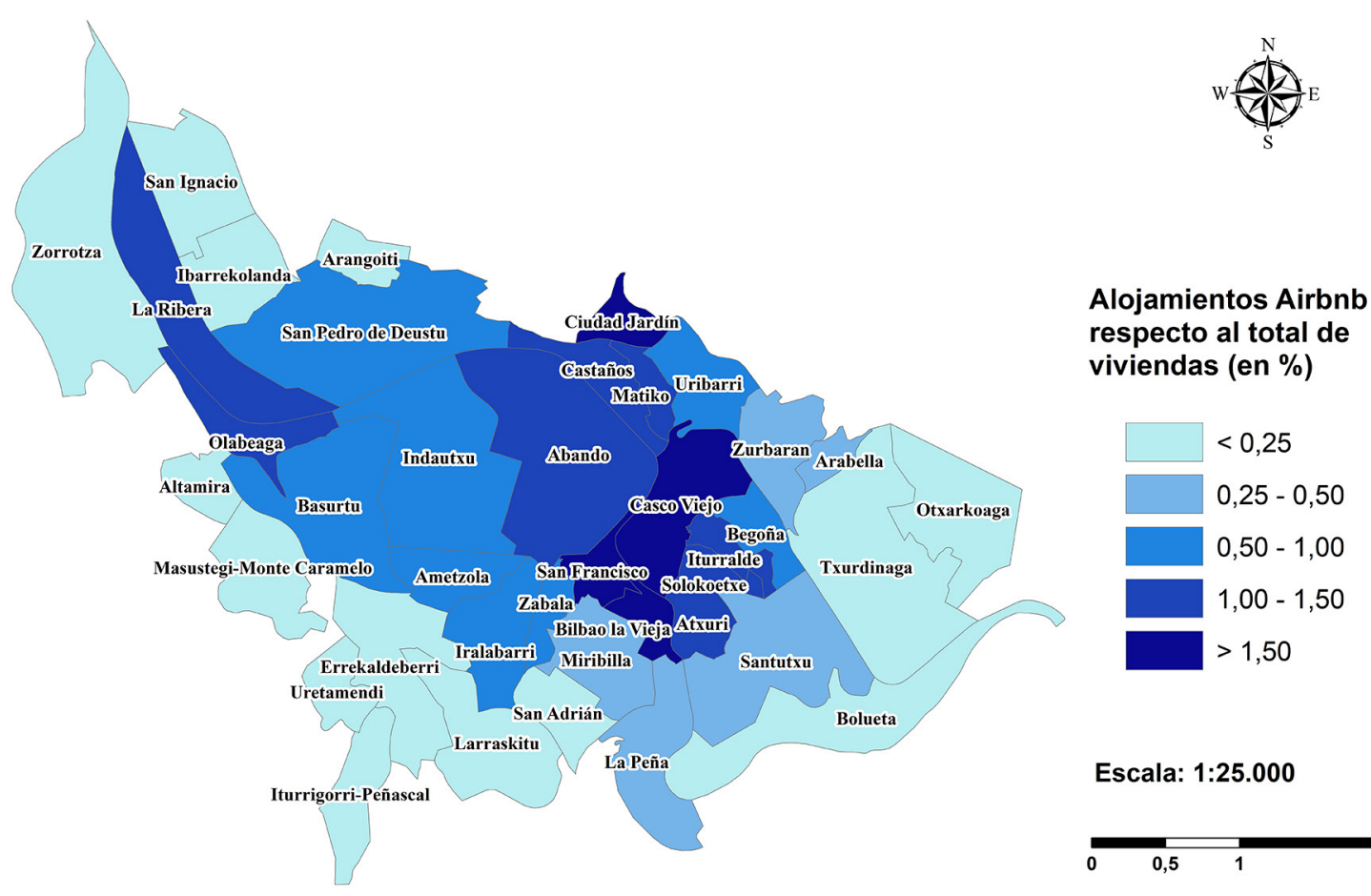

Escala: 1:25.000

Fuente: datos de Inside Airbnb (2019) y Eustat (2019d), Estadística Municipal de Viviendas. Elaboración propia 


\section{2. ¿Se puede ubicar la oferta de alojamientos de Airbnb en Bilbao dentro de la economía colaborativa o se trata de una oferta profesionalizada?}

Dos cuestiones son relevantes en relación a las preguntas formuladas en el presente epígrafe: por un lado, considerar que las prácticas de "hogar compartido" (home sharing) ponen en valor un bien infrautilizado (lo que es coherente con una mayor sostenibilidad en el uso de un recurso escaso como es la vivienda), que se ofrecen en el mercado en el periodo en el que no se están utilizando, (por ejemplo, en periodos vacacionales cuando la vivienda habitual está en desuso por sus propietarios) y que se realizan entre particulares gracias al desarrollo de las nuevas tecnologías (Gössling \& Hall, 2019). Al mismo tiempo, estas prácticas democratizan la actividad turística al hacerla más accesible tanto desde el punto de vista de los consumidores, que pueden alojarse a precios más reducidos, como de los propietarios particulares, que obtienen unas rentas suplementarias que contribuyen a mejorar la economía familiar, por lo que estas prácticas no serían comerciales y entrarían dentro del modelo de economía colaborativa. Por otro lado, el hecho de que la oferta de alojamientos turísticos se pueda estar profesionalizando y se encuentre compitiendo con la actividad turística tradicional, convierte la vivienda en un activo en el que invertir y se sitúa dentro de un modelo económico que empieza a denominarse capitalismo de plataforma (Farmaki, Christou \& Saveriades, 2020; Spangler, 2020).

En este contexto, se hace necesario concretar qué son y qué no son prácticas comerciales. Aunque hay divergencia de criterios en la literatura a la hora de diferenciar entre prácticas comerciales y actividades propias de la economía colaborativa en el ámbito de los alojamientos turísticos (véase, por ejemplo, Crommelin, Troy, Martin \& Pettit, 2018; Adamiak, 2019), hay un cierto consenso en utilizar tres indicadores fundamentales para dicha diferenciación (Kadi et al., 2019): i) el tipo de alquiler; ii) el número de alojamientos ofertados (en este caso, habría discrepancias en establecer un número determinado, aunque suelen ser uno o dos), y iii) la duración del periodo de alquiler (entendiendo que periodos superiores a tres meses, implicarían un uso exclusivamente turístico o comercial no compatible con la vivienda habitual).

En lo referente al tipo de alquiler, los autores citados clasifican la oferta en función de las tres modalidades existentes: habitaciones privadas, habitaciones compartidas y vivienda o apartamento completo. En este sentido, consideran que el alquiler de habitaciones, tanto privadas como compartidas, se ubicaría dentro del ámbito de la economía colaborativa, mientras que el alquiler de vivienda completa implicaría la existencia de un agente comercial (Ferreri \& Sanyal, 2018; Kadi et al. 2019). En el caso de Bilbao (Figura 4), de acuerdo con esta opción, destacaría la oferta de alquiler de vivienda o apartamento completo, representando un porcentaje del $51,4 \%$. Por su parte, las habitaciones privadas supondrían el $46,8 \%$ y, en cambio, las habitaciones compartidas apenas tendrían representación, con un $1,8 \%$ sobre el total.

Figura 4. Porcentaje de alojamientos ofertados por Airbnb en Bilbao según la modalidad de alquiler

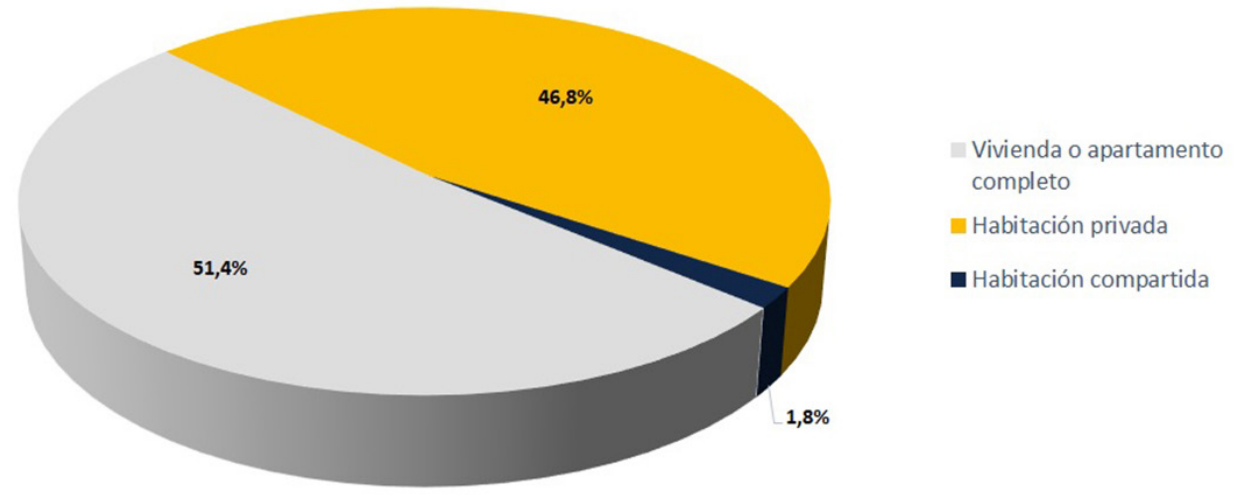

Fuente: datos de Inside Airbnb (2019). Elaboración propia

No obstante, puede haber excepciones en cuanto a la identificación de la economía colaborativa con el alquiler exclusivo de habitaciones (privadas o compartidas), ya que puede darse el caso de que la vivienda habitual se alquile durante periodos vacacionales o ausencias de sus propietarios y ello seguiría siendo economía colaborativa. Por el contrario, podría ocurrir que un agente profesional decida alquilar sus inmuebles por habitaciones, pero, en este caso, ese alquiler de habitaciones no se podría ubicar dentro 
de la economía colaborativa (Wachsmuth \& Weiser, 2018). De hecho, en la información relativa a los alojamientos de Airbnb en Bilbao se puede observar que existe una propietaria (Mercedes) que alquila cuarenta y siete habitaciones (Figura 5).

Figura 5. Modalidades de alquiler ofertadas por Airbnb en Bilbao según los propietarios con mayor número de alojamientos

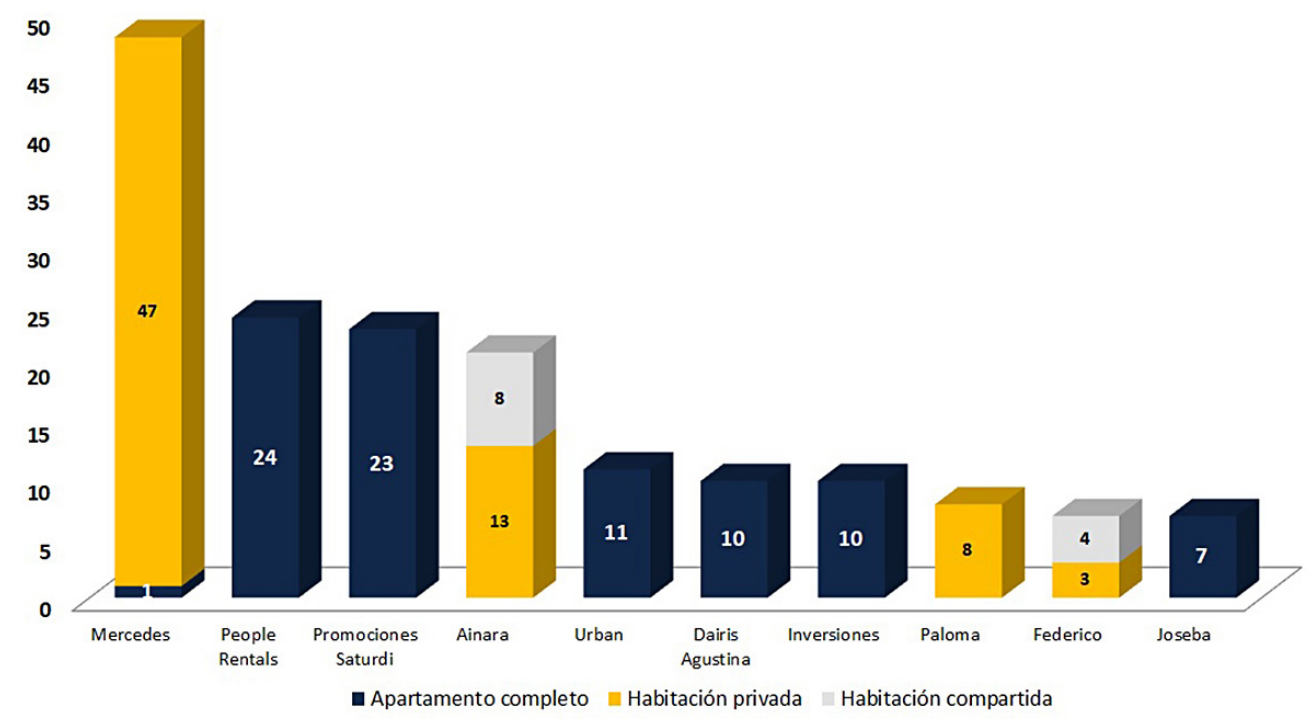

Fuente: datos de Inside Airbnb (2019). Elaboración propia

En lo relativo al número de alojamientos ofertados, se suelen considerar prácticas comerciales o propietarios profesionales a aquellos propietarios o arrendadores que alquilen más de un alojamiento (Schäfer \& Braun, 2016; Wegmann \& Jiao, 2017), puesto que se presupone que, para poder ser considerado la actividad como de economía colaborativa, lo habitual será alquilar la propia vivienda o apartamento $\mathrm{y}$, en el caso de los propietarios con mayores ingresos, podrían llegar a alquilar hasta dos viviendas o apartamentos. También, en el caso de que fuese alquiler por habitaciones, podrían ser dos unidades o incluso alguna más, aunque el hecho de que en Bilbao la superficie media por vivienda sea de 82 metros cuadrados, implica que la mayoría de las viviendas no dispongan de más de tres habitaciones, por lo que la cifra de dos unidades puede considerarse bastante representativa. Por estas razones, en el caso de aquellos propietarios que oferten dos alojamientos no se puede determinar, a priori, si se trata de propietarios particulares o de agentes profesionales.

Si se analiza el número de alojamientos ofertados por Airbnb en Bilbao atendiendo al perfil de los arrendadores (Figura 6), cabe considerar que se trata de una oferta no excesivamente profesionalizada, ya que prácticamente el $80 \%(79,8 \%)$ de los propietarios ofertan un único alojamiento. Podrían surgir dudas con aquellos propietarios que ofertan dos alojamientos (el 12,4\% de los propietarios) y que, por tanto, estrictamente, no estarían realizando prácticas de "hogar compartido". No obstante, habría que especificar si dichos propietarios están alquilando la vivienda completa o habitaciones de la misma. En este último caso, sí que se podrían computar como prácticas de "hogar compartido".

En el caso de Bilbao, se puede observar (Figura 6) que más de la mitad de los propietarios (58,0\%) que alquilan dos alojamientos, pueden catalogarse como prácticas de "hogar compartido" por tratarse del alquiler de habitaciones.

Además, el Índice de Gini, calculado sobre la distribución de los alojamientos por propietarios en Bilbao, muestra valores muy bajos $(0,13)$, lo que indica que la oferta de alojamientos se encuentra bastante repartida entre los arrendadores. La curva de Lorenz lo evidencia también así (Figura 7), mostrando una distribución bastante equilibrada al no existir una distancia relevante respecto a la diagonal. Sin embargo, es un dato significativo que sólo cinco propietarios (el 0,64\% de los ofertantes) aglutinen más del 10\% del total de alojamientos ofertados, lo que se refleja en la verticalidad que adopta la curva en los valores más positivos del eje de abscisas. Por lo tanto, aunque no se pueda hablar de una alta concentración 
de la oferta, sí cabe afirmar la existencia de dos perfiles de arrendadores u ofertantes de alquileres en la plataforma Airbnb en Bilbao: (1) arrendadores que utilizan la plataforma para obtener ingresos extras, que ofertan un único alojamiento (en torno al $80 \%$ del total) y que, por tanto, pueden considerarse propietarios particulares, y (2) arrendadores que ofertan tres o más alojamientos (en torno al $8 \%$ del total) y que se incluirían en las prácticas comerciales o el negocio inmobiliario. Con respecto al resto de arrendadores (en torno al 12\% del total), que ofertan dos alojamientos, no se puede determinar si se trata de propietarios particulares o de agentes profesionales.

Figura 6. Distribución de los arrendadores en función del número de anuncios ofertados en el listado de Airbnb en Bilbao

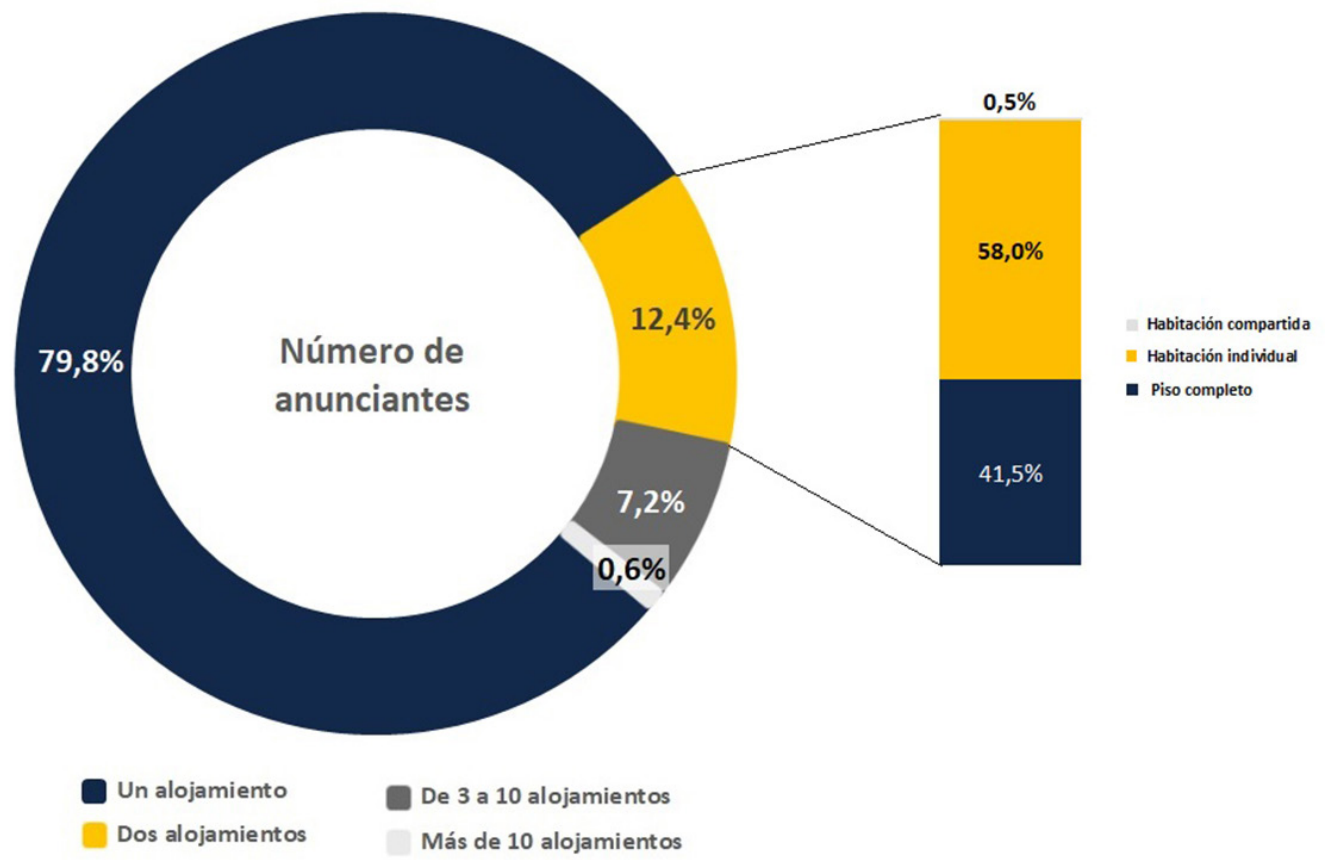

Fuente: datos de Inside Airbnb (2019). Elaboración propia

Figura 7. Curva de Lorenz de la distribución de la oferta de alojamientos Airbnb en Bilbao en relación a los propietarios

Curva de Lorenz

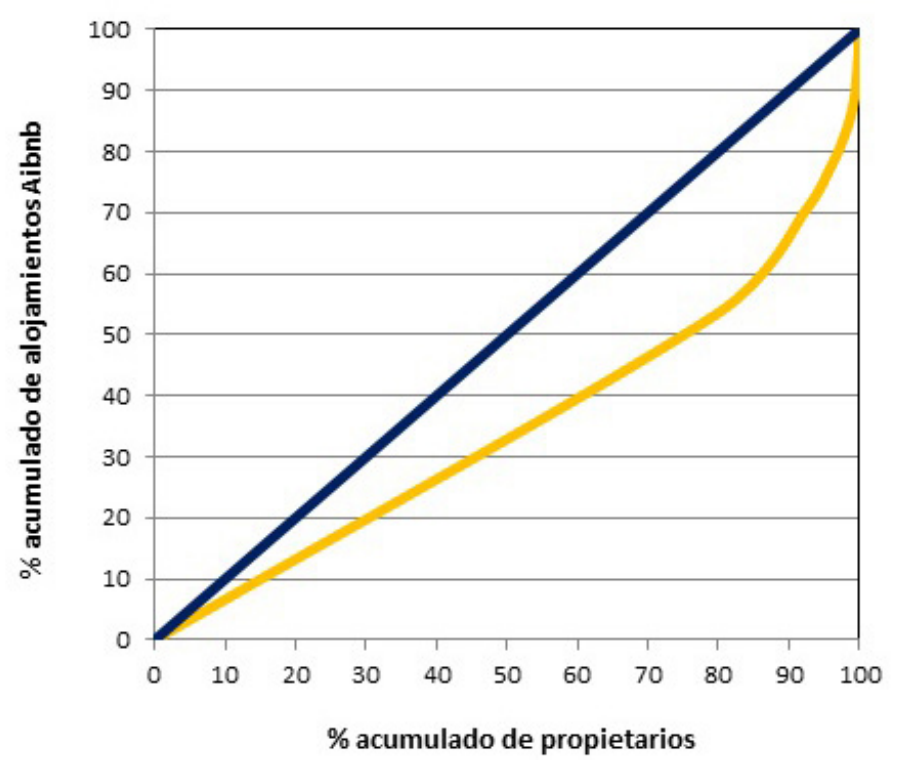

Fuente: datos de Inside Airbnb (2019). Elaboración propia 
Por último, en lo referente a la duración del periodo de alquiler, para enmarcar la actividad dentro de la economía colaborativa se debería tratar de viviendas que se alquilan en los periodos en los que no son utilizadas por sus propietarios. Por tanto, se trataría solamente de las viviendas habituales. Se entiende que para que puedan ser consideradas viviendas habituales deberían estar alquiladas por un periodo breve de tiempo, el que corresponda con los periodos vacacionales de los propietarios. De este modo, todo alojamiento que supere los noventa días de disponibilidad no podría ser considerado un bien infrautilizado, sino un alojamiento de uso exclusivamente turístico o comercial.

En el caso de Bilbao, si se observa la duración del periodo de alquiler de los alojamientos de Airbnb, se concluye que la mayor parte se refiere a inmuebles que se dedican exclusivamente al alquiler o a viviendas secundarias (Figura 8), puesto que las viviendas que se alquilan por periodos superiores a noventa días (el límite habitual que suelen establecer las administraciones públicas para determinar si se trata de una actividad privada o de una actividad comercial) representan el 52,9\%. Además, si se consideran todos los alojamientos que se ofertan en alquiler por un periodo superior a un mes, la cifra se elevaría al $67,1 \%$ del total de los alquileres, lo que pone de manifiesto que en la oferta de alojamientos de Airbnb en Bilbao predominan las prácticas comerciales o profesionalizadas.

Figura 8. Periodo de alquiler de los alojamientos de Airbnb en Bilbao

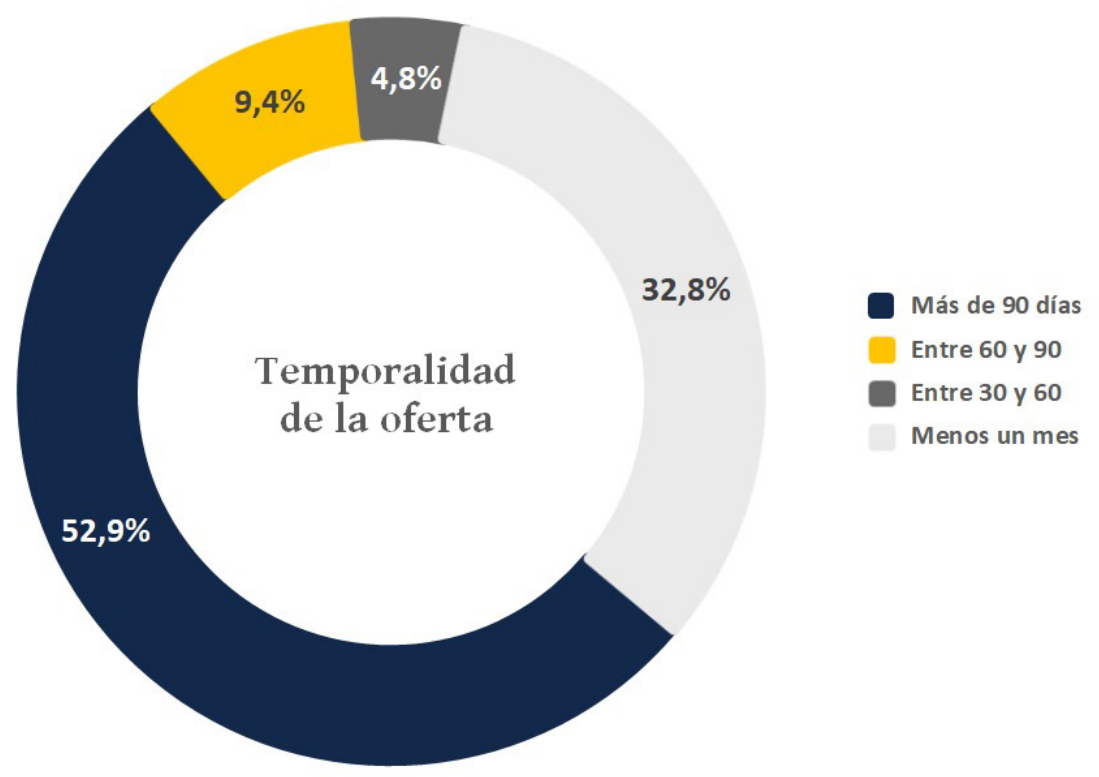

Fuente: datos de Inside Airbnb (2019). Elaboración propia

\section{3. ¿Se encuentra homogéneamente distribuida la oferta de alojamientos de Airbnb en Bilbao?}

En la Tabla 1 se observa que la distribución de los alojamientos turísticos ofertados por Airbnb en el municipio de Bilbao no es equilibrada. Así, un análisis de la información aportada por el Î́ndice de Moran confirma que existe autocorrelación espacial en la distribución de los alojamientos, viéndose influenciada por el efecto vecindad y cumpliéndose así el principio Tobler, por el cual los espacios geográficos más próximos están más relacionados entre sí que los espacios más alejados (Anselin, 1995; Xu, Hu, La, Wang \& Huang, 2019). Si se completa este análisis con el Índice de Getis-Ord (Índice G) (Getis \& Ord, 1992), se constata que se produce un agrupamiento de los valores altos, lo que indicaría la proximidad entre los barrios con mayor concentración de alojamientos turísticos mientras que, por el contrario, no existe una agrupación de los barrios con poca presencia de dichos alojamientos.

Además, si se analizan de forma específica las diferentes modalidades de alquiler, se observa que son las habitaciones privadas las que muestran un mayor agrupamiento, mientras que en el caso de las habitaciones compartidas no cabe rechazar la hipótesis nula de que exista una distribución aleatoria, dado que el Valor de $p$ es relativamente alto. Esto mismo lo confirma el Índice $G$, que también muestra que para la modalidad de habitación compartida no existe un agrupamiento espacial. 
Tabla 1. Resultados del análisis de autocorrelación espacial

\begin{tabular}{|l|c|c|c|c|}
\hline & Total & Apartamento & Habitación Privada & $\begin{array}{c}\text { Habitación } \\
\text { Compartida }\end{array}$ \\
\hline Índice de Moran & 0,157815 & 0,137586 & 0,175734 & $-0,025642$ \\
\hline Varianza & 0,001954 & 0,001856 & 0,001966 & 0,000617 \\
\hline Puntuación z & 4,073024 & 3,70905 & 4,46464 & $-0,137704$ \\
\hline Valor de p & 0,000046 & 0,000208 & 0,000008 & 0,890474 \\
\hline Tipo de distribución & Agrupada & Agrupada & Agrupada & Aleatoria \\
\hline Índice G & 0,000695 & 0,000746 & 0,000653 & 0,000286 \\
\hline z-score & 4,790146 & 4,672227 & 4,925059 & $-0,273422$ \\
\hline p-value & 0,000002 & 0,000003 & 0,000001 & 0,784528 \\
\hline Tipo de agrupamiento & Agrupamiento alto & Agrupamiento alto & Agrupamiento alto & Aleatorio \\
\hline
\end{tabular}

Fuente: datos de Inside Airbnb (2019). Elaboración propia

\section{4. ¿La oferta de alojamientos de Airbnb en Bilbao es una oferta de alquiler alternativa a la oferta hotelera tradicional o se concentra en las mismas áreas de la ciudad?}

En cuanto a la localización de la oferta, uno de los postulados que defiende Airbnb en lo que se refiere a su oferta es que permite equilibrar la oferta de alojamientos en aquellas áreas de la ciudad a las que no llega la oferta hotelera tradicional. Interesa, por tanto, identificar si se trata de una oferta complementaria a la realizada por los establecimientos hoteleros tradicionales, o si, por el contrario, compite territorialmente con ellos.

El Gobierno Vasco (2020) mantiene un registro de los alojamientos turísticos existentes en el conjunto de la Comunidad Autónoma, distinguiendo entre hoteles, hoteles-apartamentos y pensiones. Esta distinción viene regulada por el Decreto 102/2001, de 29 de mayo, que establece la ordenación de los establecimientos hoteleros ${ }^{4}$ y regula las características mínimas en cuanto a servicios, dimensiones y estancias que deben incorporar los alojamientos para ubicarse en una categoría o en otra.

En la Figura 9 se puede observar la capacidad total de la oferta de alojamientos tradicionales en Bilbao distribuida por barrios. Los azules más oscuros reflejan un mayor volumen de plazas (mediante un mapa de coropletas) y la distribución de dichas plazas en función del tipo de alojamiento: hoteles, apartamentos y pensiones (mediante un mapa de diagramas sectoriales). En Bilbao, la oferta de Airbnb llega a todos los barrios de la ciudad a excepción del barrio de Elorrieta que, como ya se indicó previamente, se encuentra en fase de construcción. En cambio, como se puede observar en la Figura 4, sólo diecinueve de los cuarenta barrios de Bilbao disponen de oferta hotelera tradicional (Gobierno Vasco, 2020). Además, esta escasez de establecimientos hoteleros se manifiesta, principalmente, en los barrios periféricos. De este modo, la mayor proporción de oferta hotelera se concentra en los barrios centrales, especialmente en Abando, Indautxu y Casco Viejo, al igual que ocurre con los alojamientos ofertados por Airbnb, por lo que se podría afirmar que puede existir cierta competencia entre la oferta hotelera y la oferta de Airbnb (Guttentag \& Smith, 2017; Benítez-Aurioles, 2018).

Interesa también conocer el detalle relativo a la competencia entre la oferta de alojamientos de Airbnb y la oferta hotelera tradicional en función del tipo de alojamiento. En el caso de Bilbao se observa que en los barrios de Abando e Indautxu predomina la oferta de la categoría de hoteles, mientras que, en Bilbao la Vieja y Ciudad Jardín, dos barrios que destacan por tener un alto porcentaje de oferta de alojamientos de Airbnb en relación al volumen de vivienda, la única oferta de plazas hoteleras tradicionales provendría de la categoría de pensiones. Por su parte, los barrios del Casco Viejo y San Francisco, que disponen de elevados porcentajes de oferta de alquileres de Airbnb, también presentan un elevado porcentaje de su oferta hotelera tradicional centrada en pensiones. De hecho, la mitad de todas las pensiones de Bilbao se concentran en el Casco Viejo.

4 https://www.euskadi.eus/bopv2/datos/textosconsolidados/200103307_vigentea.pdf 
Figura 9. Localización de la oferta hotelera tradicional en Bilbao por barrios

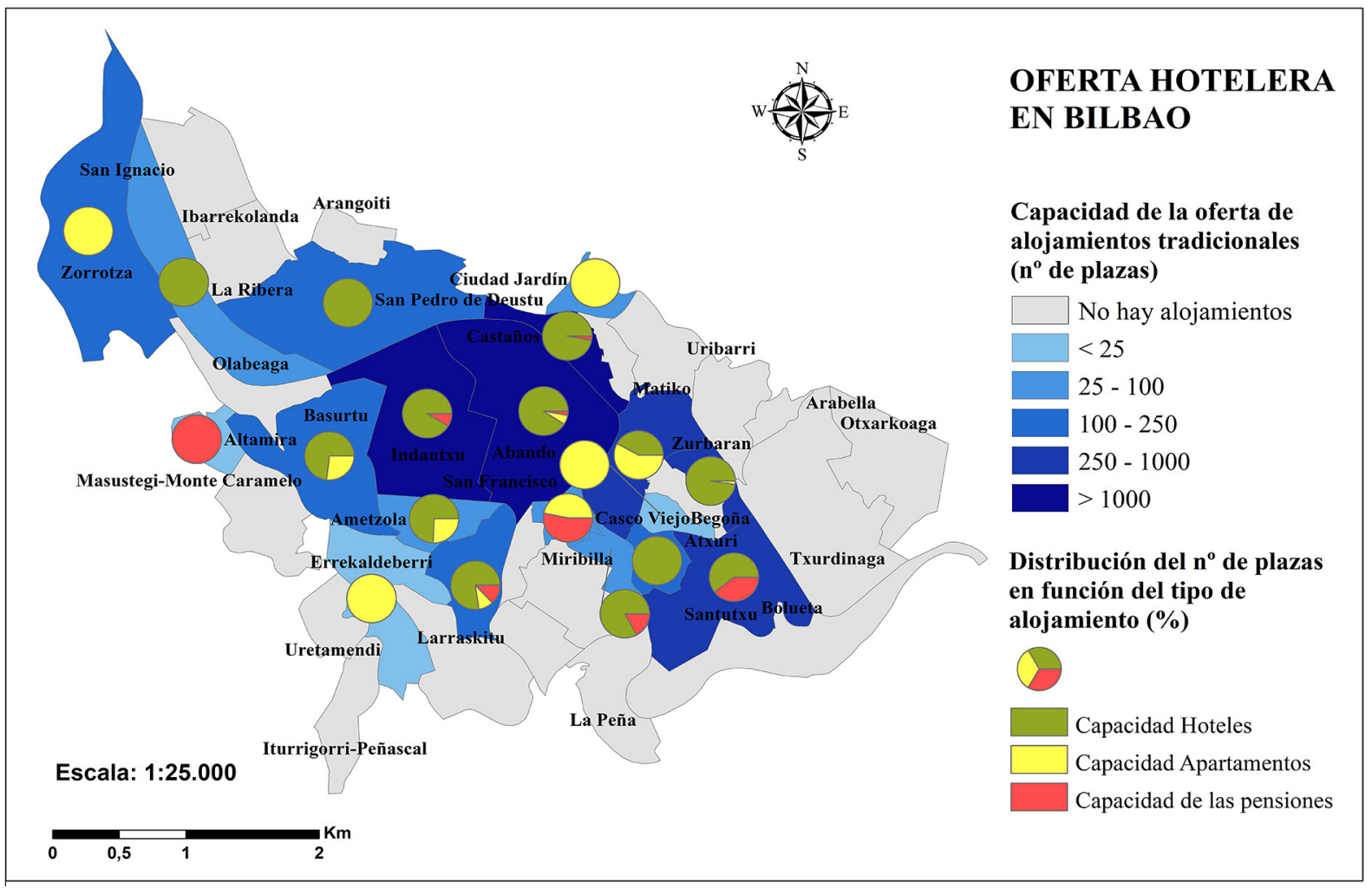

Fuente: datos de Opendata Euskadi (2020). Elaboración propia

En resumen, el análisis de la distribución espacial en el caso de Bilbao evidencia que se produce una mayor superposición entre la oferta de pensiones y la oferta de Airbnb, que entre la oferta de hoteles y la oferta de alojamientos Airbnb, por lo que, de alguna manera, se podría estar generando una mayor competencia entre la oferta de alojamientos Airbnb y la oferta de pensiones y hoteles de baja categoría, tal y como se ha señalado en estudios previos (Guttentag \& Smith, 2017; Guttentag, Smith, Potwarka \& Havitz, 2018).

Figura 10. Correlación entre la oferta de hoteles y pensiones y la oferta de alojamientos de Airbnb en Bilbao
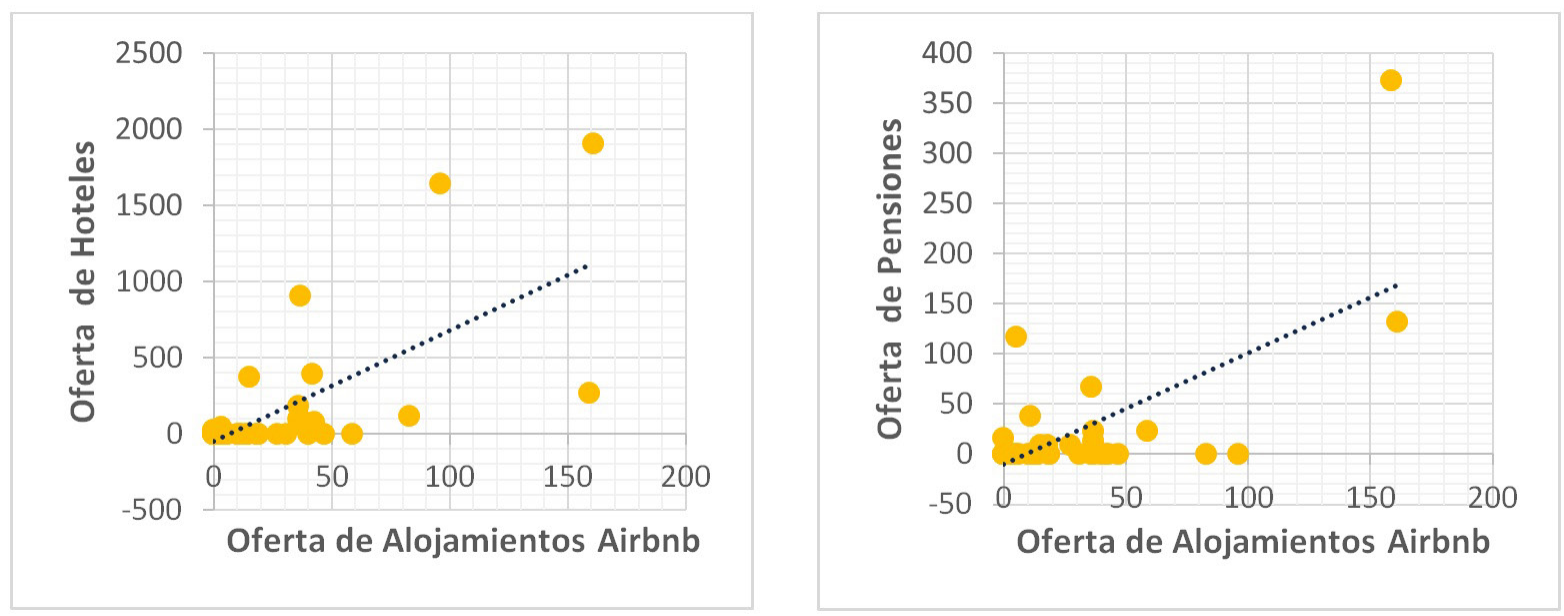

Fuente: datos de Inside Airbnb (2019) y Gobierno Vasco (2020), Alojamientos turísticos de Euskadi. Elaboración propia

Se puede concluir, por tanto, que la oferta de alquileres de Airbnb equilibra y complementa la oferta de alojamientos en la ciudad en aquellos barrios, generalmente periféricos, a los que no llega la oferta 
hotelera tradicional, generando nueva oferta en los mismos. Pero, también parece claro que los barrios que presentan mayor concentración de alojamientos turísticos son también, por lo general, aquellos donde se da mayor afluencia turística. Así lo demuestran los gráficos de dispersión (Figura 10), donde se aprecia una correlación positiva, aunque no excesivamente alta, entre la oferta de alojamientos de Airbnb y la oferta de hoteles y pensiones, con unos coeficientes de correlación de 0,68 y $0,67^{5}$, respectivamente.

\section{5. ¿Influyen las características del tejido residencial existente en los barrios en la oferta de alojamientos de Airbnb?}

Respecto a las características del tejido residencial que podrían influir en la oferta de alojamientos de Airbnb, una característica que parece estar influyendo en el caso de Bilbao es la presencia de viviendas secundarias o no principales en el barrio, ya que el coeficiente de correlación presenta un valor de $0,82^{6}$. De hecho, barrios como los de La Ribera, Ciudad Jardín, Olabeaga, Casco Viejo o Abando presentan en la ciudad mayores porcentajes de vivienda secundaria alcanzando el 31,3\%, 26,8\%, el 19,6\%, el 19,5\% o el $17,7 \%$, respectivamente (Figura 11).

Figura 11. Correlación entre viviendas secundarias y oferta de alojamientos de Airbnb en Bilbao

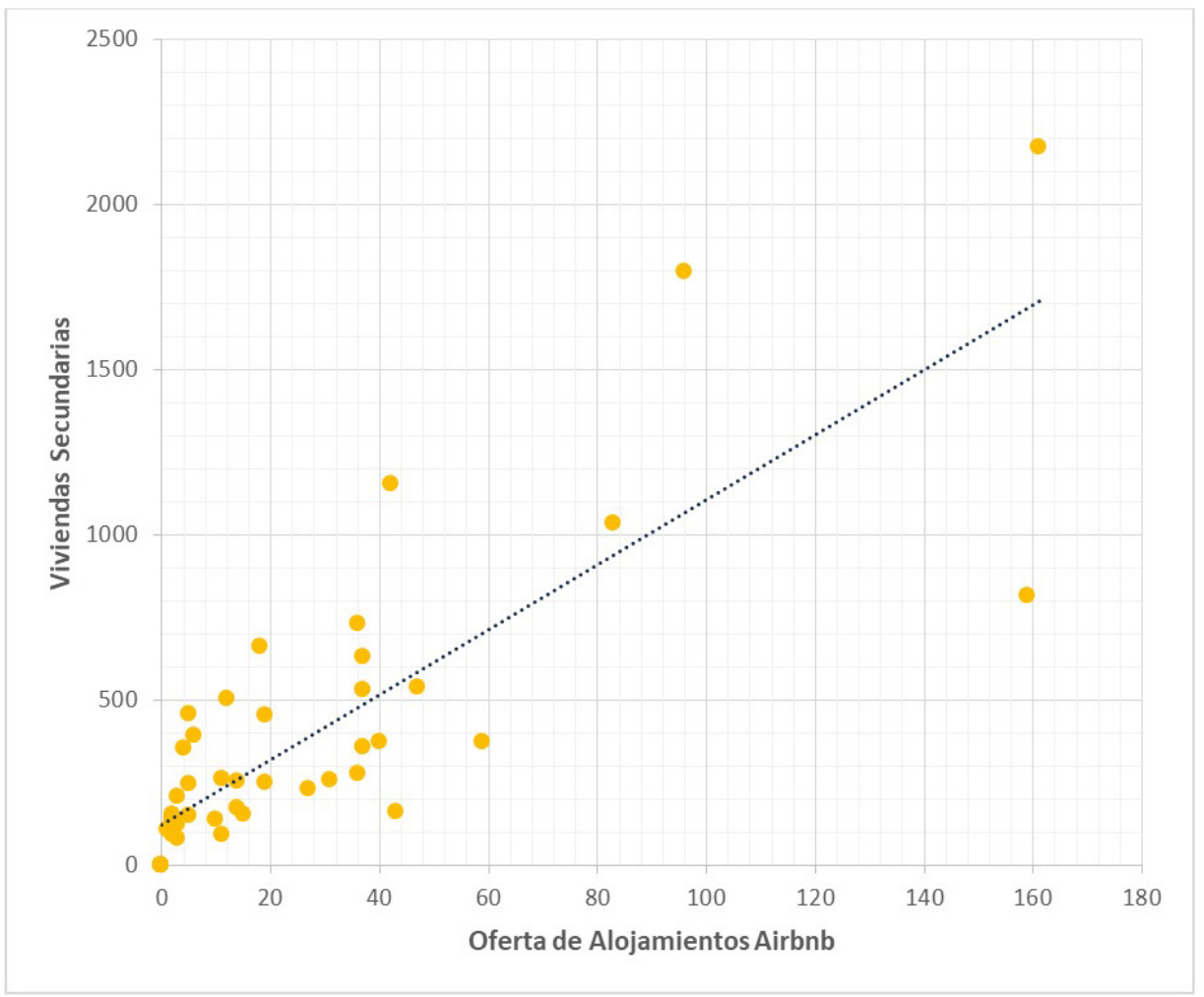

Fuente: datos de InsideAirbnb (2019) y Eustat (2019d), Estadística Municipal de Viviendas. Elaboración propia

Sin embargo, no se aprecian correlaciones altas en cuanto a otras características de las viviendas como podrían ser la antigüedad $(0,43)$, el tamaño de la unidad familiar $(0,28)$, la disponibilidad de ascensor $(0,36)$ o la disponibilidad de calefacción $(0,38)$. Aun así, parece que la oferta de alquileres de Airbnb presenta una correlación positiva, no excesivamente alta $(0,65)$, con el tamaño de la vivienda. También ofrece una correlación positiva, aunque más reducida, con la presencia en el barrio de viviendas de protección oficial en régimen de alquiler $(0,57)$, aunque no así con la presencia de vivienda de protección oficial en régimen de compra, en cuyo caso la correlación es negativa, aunque muy baja $(-0,13)$. Esto último es lógico, dado que la normativa no permite alquilar viviendas protegidas en régimen de propiedad.

5 Cálculo propio con base en los datos extraídos de las páginas web de Inside Airbnb y de la Oficina de Turismo del Gobierno Vasco. 6 Cálculo propio con base en los datos extraídos de la web de Inside Airbnb y de la Estadística Municipal de Viviendas (Eustat, 2020). 
Asimismo, se observa también una correlación positiva $(0,69)$ con el precio del metro cuadrado del alquiler de viviendas, aunque esta correlación disminuye $(0,57)$ si se considera el precio medio del alquiler (Departamento de Planificación Territorial, Vivienda y Transportes del Gobierno Vasco, 2019). Al profundizar sobre las características barriales predominantes, se observa una correlación relativamente alta entre la presencia de alojamientos de Airbnb y el nivel de renta $(0,60)$ y, especialmente, entre dicha presencia y el nivel de estudios, dado que la correlación existente entre el porcentaje de población con estudios superiores y medios y el número de alojamientos ofertados por Airbnb es de 0,74. Evidentemente, todos estos resultados son generales a nivel de barrio, por lo que no identifican las características concretas de los alojamientos ofertados por Airbnb ni las de sus propietarios, sino las características promedio de los barrios.

\section{Discusión}

Respecto a Airbnb, gran parte de la doctrina se centra en el estudio de los beneficios generales que proporciona la plataforma en comparación con los alojamientos turísticos tradicionales. Así, se destacan los efectos positivos en la creación de empleo (Dogru et al., 2020), en la democratización del turismo al ofrecer a los visitantes opciones de alojamiento más asequibles (Guttentag, 2015), en el suministro de alojamientos turísticos (Kaplan \& Nadler, 2015), en la obtención de ingresos complementarios para los anfitriones (Botsman \& Rogers, 2010), que incluso pueden contribuir a paliar la pérdida de capacidad adquisitiva para los estratos de población con menos recursos (Sperling, 2015) o en la contribución a asentar valores como la empatía, la tolerancia o el intercambio cultural (Paulauskaite et al., 2017). Y sin dejar de mencionar los efectos que Airbnb puede tener sobre la sostenibilidad, al poner en valor recursos, en este caso viviendas, que pueden encontrarse infrautilizados (Palgan, Zvolska \& Mont, 2017; Paulauskaite et al., 2017; Sung, Kim \& Lee, 2018; Contu, Conversano, Frigau \& Mola, 2019).

Sin embargo, otra parte creciente de la literatura empieza a ser muy crítica con las actividades de Airbnb, poniendo el foco en los impactos negativos que puede generar en la economía local, en el mercado inmobiliario o en la calidad de vida de los residentes (Arias Sans \& Quaglieri-Domínguez, 2016; Lee, 2016; Wachsmuth \& Weiser, 2018; Cocola-Gant \& Gago, 2019; Ioannides, Röslmaier \& van der Zee, 2019; Yrigoy, 2019; Gil \& Sequera, 2020). Algunos autores (Adamiak et al., 2019) aseguran que el modelo Airbnb supondrá una pérdida de empleo directo en el sector hotelero, mientras que otros ponen el acento en los desafíos relacionados con las regulaciones, los impuestos, la competencia desleal o la gestión de los flujos turísticos (Gurran \& Phibbs, 2017; Nieuwland \& Van Melik, 2020). Por último, otros autores han señalado que los alquileres a corto plazo han generado crecientes protestas y campañas contra el turismo urbano (Colomb \& Novy, 2016; Sheppard \& Udell, 2016), mientras que las consecuencias distributivas relacionadas con la participación selectiva en los alojamientos de Airbnb también están siendo objeto de atención (Schor, 2016).

Asimismo, la literatura señala que si la oferta de Airbnb se ubica dentro de la economía colaborativa el impacto en términos de sostenibilidad (económicos, sociales y ambientales) será positivo (Palgan et al., 2017; Paulauskaite et al., 2017; Contu et al., 2019). En este caso, no se trataría de una oferta en competencia con el sector hotelero sino complementaria a este, que se distribuiría de forma más equitativa por la ciudad, pondría en valor viviendas infrautilizadas y contribuiría a un mejor reparto de la riqueza al mejorar los ingresos de las familias. Por el contrario, cuando se trate de una oferta profesionalizada, esta puede dar lugar a una mayor concentración y con ello a procesos de turistificación, donde la vivienda se convierte en un bien de inversión que permite rendimientos económicos para las empresas y, por tanto, estas entran en competencia directa con los residentes por la adquisición de las viviendas (Cocola-Gant \& Gago, 2019; Gil \& Sequera, 2020) y con los hoteles por la atracción de turistas (Guttentag \& Smith, 2017). A modo de síntesis, en la Tabla 2, se contraponen los impactos positivos frente a los impactos negativos, que se podrían relacionar con modelos más centrados en economía colaborativa versus modelos de economía de plataforma.

En definitiva, tanto los efectos positivos como los negativos se verán también influenciados por las características y la distribución de la oferta de alojamientos turísticos en cada ciudad o territorio. En este sentido, Adamiak (2018) señala que tanto la dimensión como la orientación del municipio como destino turístico ejercen una clara influencia en la proliferación de alojamientos turísticos, pero que existen también otros factores que habría que considerar. Así, en los países del sur y del este de Europa la creciente profesionalización puede ser un síntoma de la existencia de brechas de renta, mientras que en países con 
un rápido avance de la actividad turística el crecimiento de la oferta de alojamientos turísticos permite satisfacer la demanda turística que no cubre la subdesarrollada infraestructura turística. Del mismo modo, el tipo de turismo en el que se encuentra especializado el destino turístico también contribuye a una mayor o menor expansión de los alojamientos turísticos. Los destinos costeros son más proclives a un desarrollo de este tipo de alojamientos, poniendo en el mercado, con frecuencia, la existencia de una amplia oferta de segundas residencias, mientras que el turismo de negocios no tiende a utilizar de forma habitual los alojamientos turísticos (Young, Corsun \& Xie, 2017).

Tabla 2. Impactos positivos y negativos de la economía colaborativa vs economía de plataforma

\begin{tabular}{|c|c|}
\hline ECONOMÍA COLABORATIVA & ECONOMÍA DE PLATAFORMA \\
\hline impactos positivos & impactos negativos \\
\hline $\begin{array}{l}\text { - Creación de empleo (Dogru et al., 2020). } \\
\text { - Democratización del turismo (Guttentag, 2015, Kaplan } \\
\text { \& Nadler, 2015, Botsman \& Rogers, } 2010 \text { Sperling, } \\
\text { 2015). } \\
\text { - Poner en valor recursos infrautilizados (Palgan, Zvolska } \\
\text { \& Mont, 2017; Paulauskaite et al., 2017; Sung, Kim \& } \\
\text { Lee, 2018; Contu, Conversano, Frigau \& Mola, 2019). } \\
\text { - Fomento de la cultura de compartir (Paulauskaite et al., } \\
\text { 2017). } \\
\text { - Contribución a una mayor sostenibilidad (Palgan et al., } \\
\text { 2017; Paulauskaite et al., 2017; Contu et al., 2019). }\end{array}$ & $\begin{array}{l}\text { - Competencia directa con el sector hotelero causando } \\
\text { pérdida de empleo y de ingresos en este sector (Young et } \\
\text { al., 2017; Zervas, Proserpio, \& Byers, 2017, Guttentag \& } \\
\text { Smith, 2017). } \\
\text { - Reducción en el retorno económico de los beneficios } \\
\text { generados vía impuestos y tasas (Arias Sans \& Quaglieri- } \\
\text { Domínguez, 2016). } \\
\text { - Procesos de concentración de alojamientos en } \\
\text { determinadas zonas de la ciudad y consiguiente } \\
\text { turistificación (Arias Sans \& Quaglieri-Domínguez, } \\
\text { 2016; Gurran \& Phibbs, 2017). } \\
\text { - Especulación inmobiliaria e incremento de los precios de } \\
\text { las viviendas (Wachsmuth \& Weisler, 2018; Gurran \& } \\
\text { Phibbs, 2017; Cocola-Gant \& Gago, 2019; Yrigoy, 2019; } \\
\text { Gil \& Sequera, 2020). } \\
\text { - Molestias generadas a los residentes debido a la gran } \\
\text { afluencia turística (Nieuwland \& Van Melik, 2020). }\end{array}$ \\
\hline
\end{tabular}

Elaboración propia

Para el caso de Bilbao, el análisis llevado a cabo en el presente trabajo revela una imagen compleja de la oferta de alquiler de viviendas por parte de Airbnb. La mayor o menor presencia de oferta privada ("hogar compartido") y oferta comercial difiere considerablemente según el indicador, así como geográficamente según los barrios de la ciudad. Sin embargo, el análisis muestra claramente que la oferta privada representa tan sólo una parte del total de la actividad que Airbnb despliega en Bilbao. Y, si bien esto es importante, es destacable que otra parte considerable de las propiedades ofertadas por la plataforma se destinan al alquiler exclusivo a turistas.

Así, frente a la concepción que considera que la propuesta de Airbnb es la de alquilar ocasionalmente espacio infrautilizado en la casa de alguien, tal y como sugieren habitualmente tanto la literatura sobre economía colaborativa (Paulauskaite et al., 2017; Palgan et al., 2017; Contu et al., 2019) como las campañas de marketing de la empresa, las conclusiones del presente estudio evidencian que para comprender completamente la oferta de Airbnb en la ciudad de Bilbao se exige una perspectiva más matizada que considere tanto las actividades particulares ("hogar compartido") como las prácticas comerciales. Dos son los datos reveladores a este respecto: que la proporción de viviendas que se alquilan por periodos superiores a noventa días representa más del cincuenta por ciento $(52,9 \%)$ en Bilbao, y que el alquiler de apartamento completo es la modalidad predominante. Estos datos son coincidentes con estudios previos realizados por Adamiak (2019), donde compara la situación en ciento sesenta y siete países, y por Dogru et al. (2020), que comparan la situación en cincuenta Estados de Estados Unidos. Ambos trabajos aprecian que existe una tendencia hacia la profesionalización de la oferta y que la proporción de anfitriones profesionales tiende a crecer más que la de anfitriones particulares.

A la luz de los resultados obtenidos respecto a la caracterización de la oferta de la plataforma Airbnb en la ciudad de Bilbao cabe preguntar cuál será su contribución a la economía colaborativa. A este respecto, si se atiende a los argumentos de Airbnb, "compartir el hogar" permite a los propietarios particulares participar en la prestación de servicios turísticos y, por lo tanto, beneficiarse de ellos de manera directa, 
a diferencia de los alojamientos turísticos convencionales ofrecidos por empresas y propietarios comerciales. También el análisis del presente trabajo muestra que, de hecho, Airbnb desempeña en Bilbao un papel importante en la promoción del alquiler por parte de particulares ("hogares compartidos") y, por lo tanto, desarrolla potencialmente prácticas de economía colaborativa. No obstante, el dato relativo a que los propietarios particulares compartan el espacio infrautilizado de su vivienda no aflora toda la realidad. Es cierto que, si se toma el "hogar compartido" como una indicación de prácticas de economía colaborativa, Airbnb lo facilita, pero no en la medida en la que tanto la empresa como la literatura sobre economía colaborativa lo defienden (Palgan et al., 2017; Sung et al., 2018; Gössling \& Hall, 2019).

Airbnb señala que sus actividades responden a un nuevo modelo económico basado en la economía colaborativa, especialmente en el sector del alquiler de viviendas compartidas. De hecho, argumenta que el 'hogar compartido' privado brindará mayores oportunidades para que los particulares y las familias con ingresos reducidos puedan obtener una fuente de ingresos adicional realizando una oferta diversa de alojamientos a precios más reducidos que los que realiza la oferta hotelera tradicional o las casas de vacaciones, gestionadas por propietarios que pueden permitirse comprar una propiedad adicional para alquilar. Sin embargo, no cabe afirmar tan rotundamente que la oferta de Airbnb sea, en la práctica, la de "compartir el hogar", aunque las empresas de plataformas hayan difundido la retórica del compartir (Schor, 2016; Sung et al., 2018). En consecuencia, caracterizar la oferta de Airbnb ha de ser el primer paso útil y necesario para determinar hasta qué punto la plataforma contribuye a la economía colaborativa.

No obstante, la concentración del turismo es todavía muy moderada en Bilbao con respecto a la de las grandes capitales españolas y europeas. Además, las actividades de Airbnb se distribuyen de manera desigual en Bilbao, concentrándose la oferta comercial especialmente en los barrios del centro de la cuidad (Abando y Casco Viejo) y siendo menor su presencia en los barrios periféricos. Sin embargo, si se tienen en cuenta los resultados en términos porcentuales, a los barrios centrales de Abando y Casco Viejo, se unen algunos barrios adyacentes (Bilbao La Vieja, San Francisco, Zabala, Matiko, Castaños y Ciudad Jardín) y otros dos barrios algo más alejados (como Iturrigorri-Peñascal y Olabeaga). Estos resultados van en la línea de investigaciones previas que señalan que la brecha de renta explica la conversión de los alquileres tradicionales en alquileres turísticos o vacacionales, complicando el acceso a una vivienda asequible a determinados grupos de población (Wachsmuth \& Weisler, 2018; Ioannides et al., 2019; Yrigoy, 2019; Amore, et al., 2020; Cocola-Gant \& Lopez-Gay, 2020). Asimismo, una mayor presencia de viviendas secundarias en el barrio va acompañada de una mayor presencia de alojamientos Airbnb, como ocurre en el caso de los barrios centrales de Abando y Casco Viejo y en otros dos barrios, Ciudad Jardín y Olabeaga, algo más alejados del centro, pero con elevado número de viviendas secundarias. Es decir, la vivienda principal apenas se destina al alquiler turístico, destinándose predominantemente la segunda residencia a este uso. De hecho, Adamiak (2018) señala que en las poblaciones más turísticas existe una mayor proporción de vivienda secundaria destinada a usos exclusivamente turísticos y con mayor incidencia, si cabe, en los centros históricos y en las ofertas de sol y playa.

Respecto de las consecuencias de la expansión de Airbnb en Bilbao sobre los hoteles, se observa que, por una parte, la plataforma complementa la oferta hotelera tradicional en los barrios periféricos y, por otra, compite con dicha oferta en los barrios centrales, aunque presentando una localización más distribuida por toda la ciudad que la oferta hotelera convencional. Además, Airbnb puede expandirse más fácilmente que los hoteles ya que, a diferencia de estos, no necesita edificios completos para instalarse. Todo ello les permite capitalizar, en mayor medida, su proximidad a las atracciones y lugares turísticos, como también se ha señalado en la literatura previa (Gutiérrez et al., 2017; Eugenio-Martin et al., 2019).

\section{Conclusiones}

Las contribuciones de este artículo en orden al estudio de la presencia, actuación y desarrollo de la plataforma Airbnb en la ciudad de Bilbao han sido, por un lado, ampliar la base de evidencia empírica sobre las actividades de Airbnb en una ciudad de tamaño medio y, por otro lado, cuestionar críticamente el hecho de que la oferta de alojamientos de Airbnb en dicha ciudad corresponda al modelo de economía colaborativa. En atención a todo lo expuesto en el presente trabajo, la conclusión final es que, aunque el dato de "compartir el hogar" sea un elemento importante a tener en cuenta para calificar o catalogar la estrategia de alquiler que publicita la plataforma Airbnb, también es muy significativa la oferta comercial en cuanto a la forma en que la plataforma opera en Bilbao. 
De hecho, al igual que en muchas otras ciudades, este análisis ha mostrado que en Bilbao la distribución de los alojamientos de Airbnb en el espacio urbano es selectiva y busca, fundamentalmente, localizaciones centrales y en las que exista la posibilidad de obtener mayores beneficios debido a la presencia de brechas de renta. Pero, al contrario que en otras ciudades más turísticas, todavía no se ha llegado a producir una fuerte profesionalización del sector de alojamientos turísticos, dado que el análisis también ha mostrado que todavía persiste un alto porcentaje de propietarios no profesionales.

No obstante, dado que las plataformas digitales como Airbnb, Windu o Homeway, constituyen una parte cada vez más relevante de las actividades de alojamiento turístico a nivel mundial, resulta necesario profundizar aún más en el debate sobre la relación entre las plataformas digitales y la economía colaborativa. Este trabajo supone un primer paso en esta dirección. En futuras investigaciones se deberá analizar cuáles son los factores específicos que pueden estar determinando la mayor concentración de la oferta de alquiler de la plataforma Airbnb en los barrios céntricos de muchas ciudades e indagar si ello se debe a las características del mercado de la vivienda y al surgimiento de brechas de renta, o si es debido a la localización central de esos barrios y su proximidad a los recursos y atractivos turísticos, lugares de ocio nocturno, estaciones de transporte, zonas verdes, etc. En este nuevo análisis se habrán de utilizar otras fuentes de datos que ayuden a identificar, por un lado, las características de los propietarios de los alojamientos ofertados por Airbnb (clase social, tipo de trabajo, nivel de estudios, género, etc.) y, por otro, las condiciones en que alquilan dichos espacios. Además, incluir en este nuevo análisis los datos relativos a los ingresos de Airbnb puede ayudar a conocer cómo se distribuyen los beneficios de la plataforma. Por último, como línea de investigación conexa, se debería atender a las características socio-demográficas de los barrios con mayor presencia de oferta de Airbnb en cada ciudad, pues ello permitiría conocer el impacto de la plataforma en la población local en términos de aumento de los precios de los alquileres, encarecimiento de los precios de venta de las viviendas, desplazamiento residencial, transformación comercial, pérdida de identidad, turistificación, etc.

\section{Financiación}

Este trabajo ha sido realizado gracias al apoyo del Ministerio de Economía y Competitividad (MINECO) (ECO2016-76348-R AEI / FEDER UE) y del Gobierno Vasco (IT1354-19).

\section{Referencias}

Acquier, A., Carbone, V., \& Massé, D. (2019). How to Create Value(s) in the Sharing Economy: Business Models, Scalability, and Sustainability. Technology Innovation Management Review, 9(2), 5-24. http:// doi.org/10.22215/timreview/1215

Adamiak, C. (2018). Mapping Airbnb supply in European cities. Annals of Tourism Research, 71, 67-71. https://doi.org/10.1016/j.annals.2018.02.008

Adamiak, C. (2019). Current state and development of Airbnb accommodation offer in 167 countries. Current Issues in Tourism. https://doi.org/10.1080/13683500.2019.1696758

Adamiak, C., Szyda, B., Dubownik, A., \& García-Álvarez, D. (2019). Airbnb offer in Spain—spatial analysis of the pattern and determinants of its distribution. ISPRS International Journal of Geo-Information, 8(3), 155. https://doi.org/10.3390/ijgi8030155

Aguado-Moralejo, I., Echebarria, C., \& Barrutia, J. M. (2019). Aplicación de un análisis clúster para el estudio de la segregación social en el municipio de Bilbao. Boletín de la Asociación de Geógrafos Españoles, 81, 2763, 1-35. http://dx.doi.org/10.21138/bage.2763

Airbnb, Inc. (2021). About Us. Airbnb News. Recuperado de https://news.airbnb.com/about-us/

Alfonso Sánchez, R. (2016). Economía colaborativa: un nuevo mercado para la economía social. CIRIECEspaña, Revista de Economía Pública, Social y Cooperativa, (88), 230-258. https://doi.org/10.7203/ CIRIEC-E.88.9255

Alfonso Sánchez, R., \& Burillo Sánchez, F. J. (2017). La economía llamada "colaborativa". En R. Alfonso Sánchez \& J. Valero Torrijos (dir.), Retos Jurídicos de la Economía Colaborativa en el Contexto Digital (pp. 49-72). Cizur Menor (Navarra): Thompson Reuters Aranzadi. 
Amore, A., de Bernardi, C., \& Arvanitis, P. (2020). The impacts of Airbnb in Athens, Lisbon and Milan. A rent gap theory perspective. Current Issues in Tourism. https://doi.org/10.1080/13683500.2020.174 $\underline{2674}$

Anselin, L. (1995). Local indicators of spatial association-LISA. Geographical Analysis, 27(2), 93-115. https://doi.org/10.1111/j.1538-4632.1995.tb00338.x

Arias Sans, A., \& Quaglieri-Domínguez, A. (2016). Unravelling Airbnb: Urban perspectives from Barcelona. Reinventing the Local in Tourism: Producing, Consuming and Negotiating Place, 73, 209228. Recuperado de https://www.academia.edu/24653298/Unravelling Airbnb Urban Perspectives from Barcelona

Ayuntamiento de Bilbao (2017). Bilbao adecúa su normativa a la ley vasca de turismo en relación a las viviendas turísticas. Recuperado de https://bit.ly/3csTD3n

Bashir, M., \& Verma, R. (2016). Airbnb disruptive business model innovation: Assessing the impact on hotel industry. International Journal of Applied Business and Economic Research, 14(4), 2595-2604.

Benítez-Aurioles, B. (2018). The role of distance in the peer-to-peer market for tourist accommodation. Tourism Economics, 24(3), 237-250. https://doi.org/10.1177/1354816617726211

Bilbao Turismo \& Convention Bureau (2020). Estadisticas. Recuperado de https://www.bilbaoturismo. net/BilbaoTurismo/es/datos-y-estadisticas

Botsman, R., \& Rogers, R. (2010). What's mine is yours. The rise of collaborative consumption. New York (US): Harper Collin.

Brousseau, F. (2015). Analysis of the impacts of short-term rentals on housing. San Francisco: City and County of San Francisco. Recuperado de https://sfbos.org/sites/default/files/FileCenter/Documents/52601BLA.ShortTermRentals.051315.pdf

Bruno, B., \& Faggini, M. (2017). Sharing economy: for an economic taxonomy. International Journal of Economics and Finance, 9(6), 174-178. https://doi.org/10.5539/ijef.v9n6p174

Bulchand, J., \& Melian, S. (2018). La revolución de la economía colaborativa. Madrid: LID Editorial.

Cañigueral, A. (2016). Hacia una economía colaborativa «responsable». Oikonomics, 6, 16-27. https://doi. org/10.7238/o.n6.1603

Cliff, A. D., \& Ord, K. (1970). Spatial Autocorrelation: A Review of Existing and New Measures with Applications. Economic Geography, 46(1), 269-292. https://doi.org/10.2307/143144

Cocola-Gant, A., \& Gago, A. (2019). Airbnb, buy-to-let investment and tourism-driven displacement: A case study in Lisbon. Environment and Planning A. https://doi.org/10.1177/0308518X19869012

Cocola-Gant, A., \& Lopez-Gay, A. (2020). Transnational gentrification, tourism and the formation of 'foreign only' enclaves in Barcelona. Urban Studies, 57(15), 3025-3043. https://doi. org/10.1177/0042098020916111

Colomb, C., \& Novy, J. (Eds.). (2016). Protest and resistance in the tourist city. New York: Routledge. https://doi.org/10.4324/9781315719306

Contu, G., Conversano, C., Frigau, L., \& Mola, F. (2019). The impact of Airbnb on hidden and sustainable tourism: the case of Italy. International Journal of Tourism Policy, 9(2), 99-130. https://doi.org/10.1504/ IJTP.2019.102627

Crommelin, L., Troy, L., Martin, C., \& Pettit, C. (2018). Is Airbnb a sharing economy superstar? Evidence from five global cities. Urban Policy and Research, 36(4), 429-444. https://doi.org/10.1080/08111146 .2018 .1460722

Departamento de Planificación Territorial, Vivienda y Transportes (2019). Estadísticas del Mercado de Alquiler. Recuperado de https://www.euskadi.eus/gobierno-vasco/-/estadistica-del-mercado-de-alquiler-ema/

Dogru, T., Mody, M., Suess, C., Line, N., \& Bonn, M. (2020). Airbnb 2.0: Is it a sharing economy platform or a lodging corporation? Tourism Management, 78, 104049. https://doi.org/10.1016/j. tourman.2019.104049

Duso, T., Michelsen, C., Schäfer, M., \& Tran, K. (2020). Airbnb and rents: Evidence from Berlin. SSRN Electronic Journal. https://doi.org/10.2139/ssrn.3676909 
Enciso Santocildes, M., Mugarra Elorriaga, A., Muñecas Izaguirre, I., \& Ruíz Martínez, A. (2019). Economía colaborativa vs economía de plataforma: el caso Fairbnb y sus principios inspiradores desde la economía de cooperación. Boletín de Estudios Económicos, 74(227), 259-283.

Eugenio-Martin, J. L., Cazorla-Artiles, J. M., \& González-Martel, C. (2019). On the determinants of Airbnb location and its spatial distribution. Tourism Economics, 25(8), 1224-1244. https://doi. org/10.1177/1354816618825415

Eustat (2018). Estadística de Renta Personal y Familiar. Recuperado de https://www.eustat.eus/tema_395/ opt 0/tipo 4/estad/temalista.html

Eustat (2019a). Estadística Municipal de Actividad. Recuperado de https://www.eustat.eus/tema 276/ opt 1/tipo 4/estad/temalista.html

Eustat (2019b). Estadística Municipal de Educación. Recuperado de https://www.eustat.eus/tema 271/ opt_1/tipo_4/estad/temalista.html

Eustat (2019c). Estadística Municipal de Habitantes. Recuperado de https://www.eustat.eus/bankupx/ pxweb/es/spanish/-/PX 2212 ep06b.px

Eustat (2019d). Estadística Municipal de Viviendas. Recuperado de https://www.eustat.eus/bancopx/ spanish/id 3700/indiceRR.html

Eustat (2020). Estadística Municipal de Viviendas. Recuperado de https://www.eustat.eus/estadisticas/ tema_274/opt_1/ti_estadistica-municipal-de-viviendas/temas.html

Farmaki, A., Christou, P., \& Saveriades, A. (2020). A Lefebvrian analysis of Airbnb space. Annals of Tourism Research, 80, 102806. https://doi.org/10.1016/j.annals.2019.102806

Ferreri, M., \& Sanyal, R. (2018). Platform economies and urban planning: Airbnb and regulated deregulation in London. Urban Studies, 55(15), 3353-3368. https://doi.org/10.1177/0042098017751982

Fierro, A., \& Salmón, C. (2018). El impacto del turismo en el Casco Viejo de Bilbao mediante los modelos de economía colaborativa: una aproximación a través de una distribución binomial negativa. Lurralde: Investigación y Espacio, 41, 175-201. Recuperado de http://www.ingeba.org/lurralde/lurranet/ lur41/41fierro.pdf

Franklin, A. (2016). Journeys to the Guggenheim Museum Bilbao: towards a revised Bilbao effect. Annals of Tourism Research, 59, 79-92. https://doi.org/10.1016/j.annals.2016.04.001

Freytag, T., \& Bauder, M. (2018). Bottom-up touristification and urban transformations in Paris. Tourism Geographies, 20(3), 443-460. https://doi.org/10.1080/14616688.2018.1454504

Gainza, X. (2017). Culture-led neighbourhood transformations beyond the revitalisation/gentrification dichotomy. Urban Studies, 54(4), 953-970. https://doi.org/10.1177/0042098016630507

Getis, A., \& Ord, K. (1992). The analysis of spatial association by use of distance statistics. Geographical Analysis, 24, 189-206. https://doi.org/10.1111/j.1538-4632.1992.tb00261.x

Gil, J., \& Sequera, J. (2020). The professionalization of Airbnb in Madrid: Far from a collaborative economy. Current Issues in Tourism, 1-20. https://doi.org/10.1080/13683500.2020.1757628

Gobierno Vasco (2020). Alojamientos turísticos de Euskadi. Recuperado de https://opendata.euskadi.eus/ catalogo/-/alojamientos/

González, S. (2011). Bilbao and Barcelona 'in motion'. How urban regeneration 'models' travel and mutate in the global flows of policy tourism. Urban Studies, 48(7), 1397-1418. https://doi. org/10.1177/0042098010374510

Gössling, S., \& Hall, C. M. (2019). Sharing versus collaborative economy: how to align ICT developments and the SDGs in tourism? Journal of Sustainable Tourism, 27(1), 74-96. https://doi.org/10.1080/0966 9582.2018.1560455

Gurran, N., \& Phibbs, P. (2017). When tourists move in: How should urban planners respond to Airbnb? Journal of the American Planning Association, 83(1), 80-92. https://doi.org/10.1080/01944363.2016.1 249011

Gutiérrez, J., García-Palomares, J. C., Romanillos, G., \& Salas-Olmedo, M. H. (2017). The eruption of Airbnb in tourist cities: Comparing spatial patterns of hotels and peer-to-peer accommodation in Barcelona. Tourism Management, 62, 278-291. https://doi.org/10.1016/j.tourman.2017.05.003 
Guttentag, D. (2015). Airbnb: disruptive innovation and the rise of an informal tourism accommodation sector. Current issues in Tourism, 18(12), 1192-1217. https://doi.org/10.1080/13683500.2013.827159

Guttentag, D. A., \& Smith, S. L. J. (2017). Assessing Airbnb as a disruptive innovation relative to hotels: Substitution and comparative performance expectations. International Journal of Hospitality Management, 64, 1-10. https://doi.org/10.1016/j.ijhm.2017.02.003

Guttentag, D., Smith, S., Potwarka, L., \& Havitz, M. (2018). Why Tourists Choose Airbnb: A Motivation-Based Segmentation Study. Journal of Travel Research, 57(3), 342-359. https://doi. org/10.1177/0047287517696980

INE (2020). Encuesta de ocupación hotelera. Recuperado de https://www.ine.es/jaxiT3/Tabla.htm?t=2078

Inside Airbnb (2019). Get the Data. Recuperado de http://insideairbnb.com/get-the-data.html

Ioannides, D., Röslmaier, M., \& van der Zee, E. (2019). Airbnb as an instigator of 'tourism bubble' expansion in Utrecht's Lombok neighbourhood. Tourism Geographies, 21(5), 822-840. https://doi.org $\underline{10.1080 / 14616688.2018 .1454505}$

Jarne Muñoz, P. (2016). El consumo colaborativo en España: experiencias relevantes y retos de futuro. Revista CESCO de Derecho de Consumo, (17), 62-75. Recuperado de http://hdl.handle.net/10578/20557

Kadi, J., Plank, L., \& Seidl, R. (2019). Airbnb as a tool for inclusive tourism? Tourism Geographies, 1-23. https://doi.org/10.1080/14616688.2019.1654541

Kaplan, R. A., \& Nadler, M. L. (2015). Airbnb: A Case Study in Occupancy Regulation and Taxation. University of Chicago Law Review Online, 82(1), 7. Recuperado de http://chicagounbound.uchicago. edu/uclrev_online/vol82/iss1/7

Lee, D. (2016). How Airbnb short-term rentals exacerbate Los Angeles's affordable housing crisis: Analysis and policy recommendations. Harvard Law \& Policy Review, 10, 229-253. Recuperado de https:// harvardlpr.com/wp-content/uploads/sites/20/2016/02/10.1_10_Lee.pdf

Moran, P.A.P. (1948). The Interpretation of Statistical Maps. Journal of the Royal Statistical Society, 10(2), 243-251. https://doi.org/10.1111/j.2517-6161.1948.tb00012.x

Nieuwland, S., \& van Melik, R. (2020). Regulating Airbnb: How cities deal with perceived negative externalities of short-term rentals. Current Issues in Tourism, 23(7), 811-825. https://doi.org/10.1080 /13683500.2018.1504899

Observatorio Vasco de la Vivienda (2020). GIS Observatorio Vasco de la Vivienda. Recuperado de https:// www.etxebide.euskadi.eus/x39-ovad05/es/contenidos/informacion/ovv_gises_berria/es_def/index. $\underline{\text { shtml }}$

Opendata Euskadi (2020). Alojamientos turísticos de Euskadi. Recuperado de https://opendata.euskadi. eus/catalogo//alojamientos/

Oskam, J., \& Boswijk, A. (2016). Airbnb: the future of networked hospitality businesses. Journal of Tourism Futures, 2(1), 22-42. http://dx.doi.org/10.1108/JTF-11-2015-0048

Palgan, Y. V., Zvolska, L., \& Mont, O. (2017). Sustainability framings of accommodation sharing. Environmental Innovation and Societal Transitions, 23, 70-83. https://doi.org/10.1016/j.eist.2016.12.002

Palos-Sanchez, P. R., \& Correia, M. B. (2018). The collaborative economy based analysis of demand: Study of Airbnb case in Spain and Portugal. Journal of Theoretical and Applied Electronic Commerce Research, 13(3), 85-98. http://dx.doi.org/10.4067/S0718-18762018000300105

Paulauskaite, D., Powell, R., Coca-Stefaniak, J.A., \& Morrison, A. M. (2017). Living like a local: Authentic tourism experiences and the sharing economy. International Journal of Tourism Research, 19(6), 619628. https://doi.org/10.1002/jtr.2134

Plaza, B., \& Haarich, S. N. (2015). The Guggenheim Museum Bilbao: Between regional embeddedness and global networking. European Planning Studies, 23(8), 1456-1475. https://doi.org/10.1080/09654 $\underline{313.2013 .817543}$

Quattrone, G., Proserpio, D., Quercia, D., Capra, L., \& Musolesi, M. (2016, February). Who Benefits from the'Sharing'Economy of Airbnb. EnWWW 2016: 25th International Conference on World Wide Web, (pp. 11-15). 11-15 April 2016, Montreal, Canada. https://doi.org/10.1145/2872427.2874815 
Sastre Centeno, J. M., \& Inglada Galiana, M. E. (2018). La economía colaborativa: un nuevo modelo económico. CIRIEC-España, Revista de Economía Pública, Social y Cooperativa, 94, 219-250. https:// doi.org/10.7203/CIRIEC-E.94.12109

Schäfer, P., \& Braun, N. (2016). Misuse through short-term rentals on the Berlin housing market. International journal of housing markets and analysis. International Journal of Housing Markets and Analysis, 9(2), 287-311. https://doi.org/10.1108/IJHMA-05-2015-0023

Schor, J. (2016). Debating the sharing economy. Journal of Self-Governance and Management Economics, 4(3), 7-22. https://doi.org/10.22381/JSME4320161

Sequera, J., \& Nofre, J. (2020). Touristification, transnational gentrification and urban change in Lisbon: The neighbourhood of Alfama. Urban Studies, 57(15), 3169-3189. https://doi. org/10.1177/0042098019883734

Sheppard, S., \& Udell, A. (2016). Do Airbnb properties affect house prices? Williamstown, MA, USA: Williams College Economics. Recuperado de http://www.econis.eu/PPNSET?PPN=875707955

Spangler, I. (2020). Hidden value in the platform's platform: Airbnb, displacement, and the unhoming spatialities of emotional labour. Transactions of the Institute of British Geographers, 45(3), 575-588. https://doi.org/10.1111/tran.12367

Sperling, G. (2015). How Airbnb combats middle class income stagnation. Recuperado de https://www. cedarcityutah.com/wp-content/uploads/2015/07/MiddleClassReport-MT-061915 rl.pdf

Stephany, A. (2015). The Business of Sharing: Making it in the New Sharing Economy. London: Palgrave Macmillan. https://doi.org/10.1057/9781137376183

Sung, E., Kim, H., \& Lee, D. (2018). Why Do People Consume and Provide Sharing Economy Accommodation?_A Sustainability Perspective. Sustainability, 10(6), 2072. http://dx.doi.org/10.3390/ $\underline{\text { sul0062072 }}$

Tobler, W. R. (1970). A computer movie simulating urban growth in the Detroit region. Economic Geography, 46(sup1), 234-240. https://doi.org/10.2307/143141

Wachsmuth, D., \&Weisler, A. (2018). Airbnb and the rent gap: Gentrification through the sharing economy. Environment and Planning. A, 50(6), 1147-1170. https://doi.org/10.1177/0308518x18778038

Wang, D., \& Nicolau, J. L. (2017). Price determinants of sharing economy based accommodation rental: A study of listings from 33 cities on Airbnb.com. International Journal of Hospitality Management, 62, 120-131. https://doi.org/10.1016/j.ijhm.2016.12.007

Wegmann, J., \& Jiao, J. (2017). Taming Airbnb: Toward guiding principles for local regulation of urban vacation rentals based on empirical results from five US cities. Land Use Policy, 69, 494-501. https:// doi.org/10.1016/j.landusepol.2017.09.025

Xu, F., Hu, M., La, L., Wang, J., \& Huang, C. (2019). The influence of neighbourhood environment on Airbnb: A geographically weighed regression analysis. Tourism Geographies, 22(1), 192-209. https:// doi.org/10.1080/14616688.2019.1586987

Young, C. A., Corsun, D. L., \& Xie, K. L. (2017). Travelers' preferences for peer-to-peer (P2P) accommodations and hotels. International Journal of Culture, Tourism and Hospitality Research, 11(4), 465-482. http://dx.doi.org/10.1108/IJCTHR-09-2016-0093

Yrigoy, I. (2019). Rent gap reloaded. Airbnb and the shift from residential to touristic rental housing in the Palma Old Quarter in Mallorca, Spain. Urban Studies, 56(13), 2709-2726. https://doi. org/10.1177/0042098018803261

Zervas, G., Proserpio, D., \& Byers, J. W. (2017). The rise of the sharing economy: Estimating the impact of Airbnb on the hotel industry. Journal of Marketing Research, 54(5), 687-705. https://doi.org/10.1509/ jmr.15.0204 